DOI: $10.22363 / 2312-9182-2018-22-4-788-820$

\title{
A Lexicographic Approach to the Study of Copolysemy Relations
}

\author{
Alain Polguère \\ Université de Lorraine, CNRS, ATILF \\ 44 avenue de la Libération, BP 30687, 54063 Nancy Cedex, France
}

\begin{abstract}
The notion of lexical polysemy is considered under very different angles depending on the context in which it is called on, e.g. in theoretical lexicology, practical lexicography or so-called cognitive approaches to the lexicon. We adopt an approach where polysemy is defined as a property of vocables (roughly, entries in dictionary word lists): the property to regroup several word senses, monosemy being the opposite property. Polysemy is the consequence of a more basic fact: the relation that holds between lexical units grouped within the same vocable. This relation we term copolysemy. The notion of copolysemy is required to not only account for such a well-known phenomenon as regular polysemy, but also to model the polysemy structures of vocables and the incidence these structures may have on lexical dynamics, vocabulary acquisition, analogical reasoning based on lexical information, etc. As for many other aspects of lexicology, the study of copolysemy has to be anchored in a thorough analysis of lexical data. In this paper, we present the current results of an exploration of copolysemy in French, which allowed us to systematically retrieve patterns of copolysemy (on which we believe regular polysemy is built) and achieve formal description of the polysemy structure of several thousand French vocables. The descriptive work is embedded in a large-scale lexicographic project, namely the construction of the French Lexical Network (fr-LN). Though based on the study of the French lexicon, the approach to the modeling of polysemy presented here is expected to be applicable to natural languages in general.
\end{abstract}

Keywords: polysemy, copolysemy, lexical relation, Lexical System, French Lexical Network (fr-LN), Explanatory Combinatorial Lexicology and Lexicography

\section{Лексикографический подход к изучению кополисемических отношений}

\author{
Ален Польгер \\ Лотарингский университет, CNRS, ATILF, Нанси, Франция \\ 44 avenue de la Libération, BP 30687, 54063 Nancy Cedex, France
}

Понятие лексической полисемии рассматривается с разных точек зрения в теоретической лексикологии, практической лексикографии и при так называемом когнитивном подходе к изучению лексики. В данной статье полисемия определяется как свойство вокабулы (заглавного слова словарной статьи) объединять несколько значений слова, в то время как моносемия рассматривается как противоположное этому свойство. В основе полисемии лежат отношения между лексическими единицами в рамках одной вокабулы. Такие отношения мы называем кополисемией. В статье обосновывается необходимость изучения данного явления, подчеркивается, что понятие кополисемии важно не только для объяснения хорошо известного понятия регулярной полисемии, но и для моделирования полисемической структуры вокабул, понимания того, как эта структура влияет 
на изменения в лексике, освоение новой лексики и т. д. Изучение кополисемии должно основываться на тщательном изучении лексических данных. В данной статье мы представляем последние результаты исследования кополисемии во французском языке, которое позволило нам системно выявить модели кополисемии (на которых, как нам кажется, основана регулярная полисемия) и формально описать полисемические структуры нескольких тысяч французских вокабул. Эта практическая работа является частью широкомасштабного лексикографического проекта по созданию Французской лексической Сети (fr-LN). Несмотря на то, что данное исследование провидится на материале французской лексики, такой подход моделирования полисемии может быть применен к естественным языкам в целом.

Ключевые слова: полисемия, кополисемия, лексические отночения, лексическая система, Лексическая сеть франиузского языка ( $f r-L N)$, толково-комбинаторная лексикология и лексикография

\section{ON AND AROUND THE NOTION OF POLYSEMY}

\subsection{Object of the Study}

We present a theoretical and descriptive study of lexical polysemy in French that is based on the notion of copolysemy - relation among various senses of a single word rather than directly on polysemy - property of words to express more than one meaning. The descriptive work is embedded in a large-scale lexicographic project, namely the construction of the French Lexical Network or fr-LN. Though based on the study of the French lexicon, the approach to the modeling of polysemy presented here is expected to be applicable to natural languages in general.

Section 1 examines the very notion of polysemy, which has been extensively discussed in the literature - e.g. Apresjan (1974), Béjoint (1990), Picoche (1993), Cruse (1995), Zalizniak (2007), Gries (2015), Courbon (2015), to name only a few references. Note that polysemy is often reinterpreted through the notion of ambiguity, especially in cognitive linguistic approaches: a word is said to be polysemous if its usage generates for the Addressee ambiguity in the Speaker's speech ${ }^{1}$. Ambiguity, however, will not be taken into consideration by us, and this is the third and last time we shall use this term. For us, a word is polysemous if its signifier can be used by the Speaker to express several distinct but related meanings. We adopt the perspective of the Speaker encoding a message in a linguistic utterance rather than the perspective of the Addressee decoding the Speaker's utterance.

In studying polysemy, we proceed, for the most part, according to theoretical and descriptive principles of Explanatory Combinatorial Lexicology, the lexical component of the Meaning-Text linguistic theory (Mel'čuk et al. 1995, Mel'čuk 2006a). However, this being a paper in honor of, and greatly inspired by, Anna Wierzbicka's linguistics, it is normal that we position our work relative to the Natural Semantic Metalanguage approach (Wierzbicka 1985, Goddard and Wierzbicka 2002, 2014), whenever it appears to be relevant to do so.

This "theoretical" section of the paper continues with a definition of the notion of polysemy (1.2), followed by the introduction of the indispensable, but largely

${ }^{1}$ We write Speaker, with a capital $S$, to refer to the producer of given linguistic utterances, as opposed to the speaker of a language (no capital). By analogy with Speaker, Addressee is also written with an initial capital. 
ignored, notion of copolysemy (1.3) and finally by methodological considerations on what a lexicography-based approach to the study of (co-)polysemy should be (1.4). Section 2 explains how lexicographic modeling of copolysemy relations in French is performed in the context of the construction of the French Lexical Network. Finally, Section 3 presents our model of polysemy proper, with the detailed description of copolysemy relations that were identified so far.

The following writing conventions are systematically used throughout the paper:

- names of lexical units and vocables are written in small capitals - e.g., the vocable LEG which contains the lexical units (senses) LEG I.1, LEG I.2 ...;

- the relation of copolysemy between two lexical units $\mathrm{L}_{1}$ and $\mathrm{L}_{2}$ is noted $\mathrm{L}_{1} \rightarrow \mathrm{L}_{2}$;

- names of copolysemy relations are written in non-proportional font with an initial capital letter - Conversion, Extension, Metaphor ...;

- names of Meaning-Text lexical functions are written in bold non-proportional font - Syn, Anti, Magn, Oper $i$...;

- important notions are written in sans serif font when first introduced - lexical unit, copolysemy ...

\subsection{Polysemy as "Natural" Grouping of Lexical Units}

By polysemy, we shall exclusively mean in what follows 'lexical polysemy'. The polysemy of such linguistic entities as grammatical constructions (Apresjan 1974: 5-6, Goddard 2000: 140-144) will not be considered. We believe grammatical polysemy to be quite distinct from lexical polysemy both in its structural organization and in the methodology that ought to be applied in order to explore and model it. There surely are important connections to be established between the two phenomena, but we are in no position to propose any significant insight on this topic.

Let us start with the definition of lexical polysemy, as it is used in the present study. In order to formulate such definition, two preliminary notions have to be specified: lexical unit and vocable.

Definition 1. A lexical unit of a given language is a linguistic entity characterized by a specific meaning expressed in that language either by wordforms - in which case the lexical unit is a lexeme, e.g. SOFA — or by semantically non-compositional phrases - in which case it is an idiom, e.g. LOVE SEAT.

A lexical unit can be considered as being an abstraction over a set of linguistic signs. A lexeme, in particular, is the set of all wordforms that are inflectional variants expressing the same lexical meaning: SOFA $=\{s o f a, s o f a s\}$. It is essential to consider that, when dealing with lexical units, three elements have to be simultaneously taken into consideration: 1) the meaning of the lexical unit, 2) the form that expresses this meaning and 3 ) the individual combinatorial properties of the whole ${ }^{2}$.

Two or more lexical units can entertain a remarkable semantic and formal relation that justifies their grouping within higher level lexical entities than lexical units, namely vocables.

2 This tripartite perspective on lexical units is a direct consequence of the Meaning-Text conceptualization of linguistic signs as triplets consisted of a signified (meaning), a signifier (form) and a syntactics (combinatorial properties). For a detailed presentation, see Mel'čuk (2006b: Chapter 7). 
Definition 2. A vocable is either (i) a multi-element set containing lexical units whose forms of expression are identical and whose meanings, while different, display a significant intersection, or (ii) a singleton comprised of only one lexical unit for which there exists no other lexical unit that could be grouped with it in such a way.

Let us take the vocable BALCONY as illustration. It groups together two lexical units: BALCONY $\mathbf{1}$ [on the façade of a building] and BALCONY $\mathbf{2}$ [in a theater]. Both BALCONY $\mathbf{1}$ and BALCONY 2 are expressed by the same signifiers (balcony, balconies) and though their meanings are distinct, one clearly perceives a significant semantic connection between them. It is, of course, possible to argue for the existence of a unique, extremely vague lexical unit BALCONY carrying a generic lexical meaning 'balcony', to which various contexts - balcony overlooking the square vs. to sit at the front row of the (theater) balcony - would "give" a potentially unlimited number of richer derived meanings. It is no place to debate such extreme contextualist approach to lexical semantics - for a discussion, see Polguère (2015). Our main reasons for postulating two separate units BALCONY 1 and BALCONY 2 are the following:

- both lexical units denote architectural elements of totally different wholes a façade wall vs. a theater hall;

- each of them controls its own specific network of paradigmatic and syntagmatic lexical relations (called its lexical cluster in 3.1 below) - BALCONY $\mathbf{1} \rightarrow$ wall, façade, balustrade, $\sim$ overhangs sth., to sit on $a \sim \ldots$ vs. BALCONY $2 \rightarrow$ theater, parterre, stage, seat, to sit in the ...;

- in the context of language teaching, it is not unreasonable to present BALCONY 2 as a metaphorical derivative of BALCONY 1 based on shape analogy.

Two important remarks about the notion of vocable have to be made. Firstly, as the above definition shows, there are in fact two kinds of vocables: those that contain more than one lexical unit - e.g. BALCONY and ARM (of a person vs. an animal vs. an object $v s$. a company) - , qualified as being polysemous; 2) those that contain just one lexical unit - e.g. RHINOCEROS and TETRAHEDRON - , qualified as being monosemous. The former type is considered by us to be the default one and the latter type a marked case (see 1.4.1 below). One may wonder why the notion of vocable should also encompass "isolated" lexical units. This is justified both for theoretical and practical reasons which will become clearer shortly. The second important remark about the notion of vocable concerns the criterion of "significant meaning intersection". What makes a meaning intersection significant? For instance, seals in (1a) and seal in (1b) below will be considered as being two wordforms of lexemes which are not connected by a significant meaning intersection and therefore belong to two separate vocables, or homonyms ${ }^{3}$.

(1) a. There used to be a large population of seals in the Dutch delta region.

b. Any document bearing the impression of the royal seal was as good as a direct command of the King.

To ensure naturalness, our examples are not constructed by us. They are extracted from corpora or from the Internet; some are slightly doctored for readability purposes. This remark does not apply to Section 3 where very compact examples illustrating senses of vocables are needed for practical reasons. 
However, these wordforms do possess a semantic intersection, if only the very general meaning 'physical entity'. This meaning is probably much too vague to be considered as being significant, when compared to the rich semantic intersection that is found between BALCONY $\mathbf{1}$ and BALCONY $\mathbf{2}$ mentioned above. But more importantly, what makes the latter intersection significant is the fact that, as speakers of English, we do not wish to consider that the formal identity of BALCONY $\mathbf{1}$ and BALCONY $\mathbf{2}$ is unrelated to their semantic intersection. In other words, we do consider that the formal identity bears semiotic significance and this significance justifies the grouping within a single vocable. The notions of significant meaning intersection and semiotic significance are related to what Apresjan (1974: 14-16) calls non-trivial common part (of lexical meanings and, therefore, of lexicographic definitions).

The formal similarity and meaning intersection that connect two lexical units $\mathrm{L}_{1}$ and $\mathrm{L}_{2}$ can be envisaged according to two perspectives, either separately or simultaneously: synchronic $v s$. diachronic perspectives.

Synchronic perspective: One may consider that, in the current state of the language, it is part of our lexical competence to acknowledge the semantic relation between $\mathrm{L}_{1}$ and $\mathrm{L}_{2}$ as being significant and non-coincidental, and that this acknowledgment allows us to better grasp the way both $\mathrm{L}_{1}$ and $\mathrm{L}_{2}$ should be used - for instance, the fact that they share non-trivial combinatorial properties, such as the two senses of bombardment in $(2 \mathrm{a}-\mathrm{b})$ below which control the same collocative intensifier heavy while having totally different meanings.

(2) a. Rebel-held areas of the city came under heavy bombardment.

b. The minister stormed out of the interview after a heavy bombardment of questions.

Diachronic perspective: One may believe/know that $\mathrm{L}_{2}$ is an offspring of $\mathrm{L}_{1}$ in the history of the language. In this case, what matters most is the (right or wrong) belief that the existence of $\mathrm{L}_{2}$ in the language lexicon is the result of a process of lexical creation by which the signifier of $\mathrm{L}_{1}$ has been "recycled" to express a new (= not associated to this signifier before) meaning because it is closely related to the meaning of $\mathrm{L}_{1}$ in one way or another.

Both perspectives interact in the mind of speakers of the language, but it is healthy for lexicologists and lexicographers to clearly identify which one they adopt. Eventually, they may precisely want to focus on the interaction between synchronic and diachronic facts, but they have to state it explicitly. Nothing new here and it is a methodological principle that has been made clear at least since F. de Saussure. The present study is conducted from a strict synchronic perspective. This means that we do not presuppose any actual knowledge of the history of the language when deciding whether or not to group two lexical units within the same vocable. What matters is the semiotic significance or the "naturalness" of the grouping of lexemes for a hypothetical Speaker, totally unaware of diachronic facts when lexicalizing her/his thoughts. Clearly, such Speaker is a theoretical construct, but one that is useful and, even necessary, for conducting lexicographic work. We are, of course, fully aware that this way of proceeding is insufficient if one wants to account for what takes place in the mind of individuals 
when they use natural languages. It is, however, a necessary first step, the only one that allows for the actual construction of lexical models, as imperfect and incomplete as they may be.

Based on the above discussion of the two basic notions of lexical unit and vocable, we can propose a rather simple and straightforward definition of the notion of polysemy as it is used in this paper ${ }^{4}$.

Definition 3. Polysemy is the property of a vocable to contain more than one lexical unit.

There is a striking difference between the above definition of polysemy and definitions usually found in the literature: our definition is absolutely minimal as it is entirely derived from the notion of vocable which, in our opinion, is primary. Therefore, vocables come first, as natural groupings of lexical units, and polysemy comes next, as property of a given vocable of not being a singleton. Apresjan (1974)'s definition of polysemy ${ }^{5}$, for instance, is constructed around the undefined notion of word, which obviously cannot correspond to our notion of lexical unit but rather to that of vocable. To put it differently, definitions such as Apresjan's define polysemy by trying at the same time to partly explain what is meant by word.

Though the notion of polysemy is built on that of vocable, one should note that if polysemy did not exist in natural languages - i.e. if all vocables were monosemous there would be no need for the notion of vocable in lexicology. This fact explains why researchers who are either not particularly interested in polysemy or are negating its relevance outright do not feel the need for a distinct notion of vocable; the terms dictionary entry or word suffice to satisfy their metalinguistic needs ${ }^{6}$.

\subsection{From the Property of Polysemy to the Relation of Copolysemy}

\subsubsection{Definition of Copolysemy}

Contrary to homonymy, that is conceived of by linguists as well as laypeople as a relation between two words (formally identical but with unrelated meanings), polysemy is commonly envisaged as a property of words ${ }^{7}$. There is therefore no possible direct connection between polysemy (a property) and homonymy (a relation); these

4 Terminological remark: this notion of polysemy does not belong to the standard notional system of Explanatory Combinatorial Lexicology, our theoretical framework of reference. For I. Mel'čuk, polysemy is not a property and the term polysemy is to be equated with polysemy relation. It is therefore more or less equivalent to our own term copolysemy, introduced below (Subsection 1.3).

5 "The word $A$ is called polysemantic if for any two of its meanings $a_{i}$ and $a_{j}$ there exist meanings $a_{1}, a_{2}, \ldots, a_{k}, a_{1}$ such that $a_{i}$ is similar to $a_{1}, a_{1}$ to $a_{2}$, etc., $a_{k}$ to $a_{1}$ and al to $a_{j}$ "' (Apresjan 1974: 14).

6 We found in the literature an interesting substitute for the term vocable, namely: [a] polysemy. See Traugott and Dasher (2001: 11) when they talk about sense creation through polysemy: "Our theory of meaning embraces the hypothesis that families of related meanings, or polysemies, can, and indeed must be identified." This terminological practice is preaching by the example as it makes the vocable POLYSEMY be polysemous.

${ }^{7}$ We allow ourselves to use word - which is not part of our terminology - when it is appropriate to remain vague; for instance, when adopting a layperson's perspective on language. 
notions are indirectly connected. To illustrate this conceptualization of polysemy as property, let us briefly examine how two renown general language dictionaries, the Longman Dictionary of Contemporary English ${ }^{8}$ and the American Heritage Dictionary of the English Language ${ }^{9}$, describe the term polysemy. First of all, they have no entry for it! They have an entry for the adjective polysemous, defined approximately by the formula: "[a word] that has more than one meaning". The adjectival entry mentions a corresponding noun polysemy, without any definition, as if this noun were a semantic derivative of the adjective polysemous. From this, we can infer an implicit definition of the noun polysemy, something like: "property of a word such that it is polysemous". This illustrates clearly to what extent polysemy is conceptualized as a property of something, and not as a relation between two things. And this is perfectly in accordance with the definition we proposed for this notion in Subsection $1.2^{10}$.

Now, while polysemy is a property of a vocable, it is indeed based on a relational fact, i.e. the existence of one or more lexical relations within the lexicon. If vocable $\mathrm{V}$ is polysemous, it is because there exist at least two lexical units in the language that are linked by a complex formal and semantic relation $\rightarrow$ (characterized in Subsection 1.2 and still unnamed for now) and whose grouping constitutes V. In other words:

$$
\mathrm{L}_{1} \rightarrow \mathrm{L}_{2} \quad \Rightarrow \quad \mathrm{V}=\left\{\mathrm{L}_{1}, \mathrm{~L}_{2} \ldots\right\} \text {. }
$$

Interestingly, there is to our knowledge no established term that denotes the $\rightarrow$ relation holding between two lexical units of the same vocable. There exist terms to denote specific types of $\rightarrow$ - lexical metonymy, lexical metaphor, etc. - - but nobody seems to have cared to name the generic relation itself since the original coinage of the term polysémie by the French philologist Michel Bréal (Bréal 1897: Chapters IX and $\mathrm{X})^{11}$. When the recourse to the underlying $\rightarrow$ relation is needed, the term polysemy is used as if it were denoting a relational fact, for instance by mentioning a relation of polysemy or the polysemy relationship — see, for instance, Sigman and Cecchi (2002) or current practice in Explanatory Combinatorial Lexicology described earlier in Footnote 4.

To fill this terminological gap, we propose two essential notions: copolysemy and copolyseme (Polguère 2016a: Chapter 7).

Definition 4. Copolysemy between two lexical units $\mathrm{L}_{1}$ and $\mathrm{L}_{2}-$ symbolized as $\mathrm{L}_{1} \rightarrow \mathrm{L}_{2}$ - is the formal and semantic relation linking $\mathrm{L}_{2}$ to $\mathrm{L}_{1}$ which conditions their grouping within the same polysemous vocable.

The above definition implies that, by default, the relation of copolysemy is oriented, from $\mathrm{L}_{1}$ to $\mathrm{L}_{2}$; this is the reason why we chose the arrow-like symbol " $\rightarrow$ " to represent it. More precisely, $\mathrm{L}_{1} \rightarrow \mathrm{L}_{2}$ implies that, in the couple of formally identical lexical units

${ }^{8} \mathrm{https}: / / \mathrm{www}$. ldoceonline.com.

$9 \mathrm{http}: / /$ www.ahdictionary.com.

${ }^{10}$ Note that Apresjan (1974)'s definition - quoted in Subsection 1.2, Footnote 5 - is also using polysemous as starting point (more precisely, polysemantic) rather than the noun polysemy itself.

${ }^{11} \mathrm{M}$. Bréal being a philologist, he is primarily concerned by the dynamic phenomenon of word creation through polysemy (diachronic perspective). For this reason, his term polysémie denotes a specific process of "sense multiplication" rather than a property of a vocable: "Nous appellerons ce phénomène de multiplication la polysémie" (Bréal 1897: 154-155). 
$\mathrm{L}_{1}$ and $\mathrm{L}_{2}$, it is the meaning of $\mathrm{L}_{2}$ that is perceived as existing relative to the meaning of $\mathrm{L}_{1}$. We use the vague formulation relative to in order to avoid the more specific derived from. Section 3 will provide reasons for this choice of terms, which relates to the fact that the directionality of an $\mathrm{L}_{1} \rightarrow \mathrm{L}_{2}$ relation does not imply that the meaning of $\mathrm{L}_{2}$ is constructed from the semantic material found in the meaning of $\mathrm{L}_{1}$.

In relation to this, note that symmetric configurations of copolysemy relations $\mathrm{L}_{1} \leftrightarrow \mathrm{L}_{2}$, where copolysemy holds both from $\mathrm{L}_{1}$ to $\mathrm{L}_{2}$ and from $\mathrm{L}_{2}$ to $\mathrm{L}_{1}$, are a theoretical possibility - though we have no concrete example to offer. It goes without saying that symmetric configurations of copolysemy relations can only be envisaged within a purely synchronic approach. In the context of diachronic studies, it would be contradictory to consider that a lexical unit $\mathrm{L}_{2}$ can simultaneously originate from another lexical unit $\mathrm{L}_{1}$ and be the origin of $\mathrm{L}_{1}$.

To complement our notional toolkit and conclude on the presentation of copolysemy, we need a relational term denoting lexical units involved in a copolysemy relation $\left(\mathrm{L}_{1}\right.$ and $\mathrm{L}_{2}$ involved in $\mathrm{L}_{1} \rightarrow \mathrm{L}_{2}$ ).

Definition 5. Copolysemes are lexical units that belong to the same vocable they are connected either directly or indirectly by a copolysemy relation within this vocable.

It is necessary to take into consideration both direct and indirect copolysemy relations between copolysemes because in cases like $\mathrm{L}_{1} \rightarrow \mathrm{L}_{2} \rightarrow \mathrm{L}_{3}$, for instance, we want to consider $\mathrm{L}_{1}$ and $\mathrm{L}_{3}$ to be copolysemes within their vocable. The relation of copolysemy is therefore transitive.

\subsubsection{Regular Polysemy and Lexical Dynamics}

Polysemy would not be that interesting a phenomenon if there were no regular polysemy: patterns of copolysemy relations that are recurrently instantiated in natural language lexicons. Regular polysemy is believed to be an essential vector of word creation. In his seminal publication on regular polysemy, Yuri Apresjan highlights the direct connection between polysemy and lexical productivity (Apresjan 1974: 18): there obviously is an intimate connection between the two phenomena. Consequently, within a synchronic approach to polysemy, it would be a mistake to lose sight of the fact that "underlying the state of affairs [of polysemy] is a process" (Hanks 2013: 357). In the synchronic study of polysemy, lexical dynamics (Traugott and Dasher 2001, Vanhove 2008, Hanks 2013, Ludlow 2014) will always play the role of the uninvited guest.

However, caution is required when establishing the connection between polysemy (or copolysemy) and lexical dynamics, more specifically sense creation. The copolysemy relation $(\rightarrow)$ is not necessarily the result of a diachronic change $(>)$. Two lexical units with identical signifiers and with significant meaning intersection, with a perceived copolysemy linkage, may very well possess their own parallel history, the resulting formal and semantic relatedness being perfectly coincidental - for a discussion and illustrations, see Traugott and Dasher (2001: 13-14). Conversely, some synchronic homonymy can be the result of the historical degeneration of a copolysemy relation, where semantic proximity is no longer perceived. A classical illustration is found 
in French with the two homonyms VOLER ${ }^{1}$ 'to fly' and VOLER ${ }^{2}$ 'to steal' which are probably related in diachrony through a now extinct use of VOLER ${ }^{1}$ in falconry (Ullman 1959: 326).

At this point, we are equipped with essential notions that will allow us to conduct a rigorous lexicographic study of polysemy (Sections 2 and 3). Before we proceed, let us comment on some basic facts about the methodology that guides such study.

\subsection{Methodological Considerations}

\subsubsection{Anticipating Polysemy}

This paper's approach to polysemy is different from that of Natural Semantic Metalanguage mainly in the way it considers polysemy in the lexicographic process. As stated by Goddard (2000: 132): "The NSM [= Natural Semantic Metalanguage] school follows the traditional 'definitional' approach (Geeraerts 1994) to lexical polysemy. One assumes to begin with that there is but a single meaning, and attempts to state it in a clear and predictive fashion, in the form of a translatable reductive paraphrase. Only if persistent efforts to do this fail is polysemy posited". Contrary to Natural Semantic Metalanguage, we postulate, when dealing with a given vocable, that it contains more than one single sense - i.e. that it is polysemous - and only if no evidence can be found of the presence of separate senses is monosemy accepted.

There are two reasons for proceeding this way. Firstly, it is the recognition of the fact that polysemous creation is one of the main vectors of lexical dynamics (Subsection 1.3.2 above). Word creation is, of course, performed by creating morphologically derived or totally new signifiers for new lexical signifieds; but it is also very commonly performed by associating new lexical signifieds to existing lexical signifiers with which they entertain a meaning relation (extension, metonymy, metaphor, etc. Section 3 below). Even within a conservative lexicographic approach to polysemy, where proliferation of senses is not welcome in lexicographic descriptions, it is somehow rare to be faced with monosemous vocables, especially if specialized vocabulary, such as names of chemical molecules, botanical species, etc., is left aside. The second reason why polysemy is postulated by default is that our focus is not lexical meanings and their lexicographic definition per se, but lexical units as wholes: which includes their meaning, of course, but also their combinatorial properties and, more generally, all differentiating lexicographic information (Mel'čuk 2013: Chapter 11, 3.2.2) that may demonstrate its singularity. It is often the case that meanings that can be blended together when considered from a strictly conceptual perspective (e.g. I, as an individual describing language, decide that house balconies and theatre balconies are the same kinds of entities) are better considered as related to two separate meanings when taking into consideration how the corresponding word behaves in actual speech.

An important methodological consequence in lexicographic analysis of what has just been stated is that the very first operation performed when conducting the description of a vocable should be to make an initial hypothesis about its polysemy structure ${ }^{12}$.

12 The notion of polysemy structure, as understood here, is presented in Subsection 2.2 below. 
Lexicographers should first try to identify — through introspection and the study of occurrences in oral and written texts - the various senses that can be expressed by a given word. True, the distinction may sometimes be hard to establish at first, without digging deeper into the word behavior, such as for legs and leg in (3a-b).

(3) a. He put on his jacket hood, crossed his legs, folded his arms and let his head fall. [ $\rightarrow$ leg of a human being]

b. Up on a plank, high above her in the sky, was a black cat who was making slurping noises as he licked his leg.

$[\rightarrow$ leg of an animal]

More often than not, however, one can safely hypothesize the presence of polysemy, for instance, when contrasting ( $3 \mathrm{a}-\mathrm{b}$ ) above with (4).

(4) These grand piano leg dollies are manufactured in the United States.

$[\rightarrow$ leg of an object $]$

Note that, if it is doubtful that we are with (3a-b) and (4) in the presence of one single meaning, some may argue that (4) involves a totally unrelated lexical unit, which would boil down to rejecting the very notion of polysemy and replace it with wall-to-wall homonymy. We believe such approach to be counterproductive if one wants the lexicographic description to be compatible with perceived semantic connections - semantic bridges - by the Speaker and with resulting usage in speech: wordplay, teaching and acquisition by metaphor, etc. Sentence (5), for instance, makes sense only if we understand that the Speaker presupposes a link of metaphor between two senses of leg cf. the term analogy.

(5) Buñuel had already played with the piano leg/woman's leg analogy in his earlier film Tristana.

\subsection{2. "Back to Definitions" (Wierzbicka 1992)}

A common credo the present study shares with Natural Semantic Metalanguage, and with Apresjan (1974)'s approach as well, is that the key to polysemy is to be found in lexicographic definitions. There is no polysemy without copolysemy relations between senses, and there is no copolysemy relation - in the most standard cases - without corresponding semantic bridges or other, more indirect, form of connection between the respective definitions of copolysemes. Consequently, copolysemy will be solely postulated based on actual or hypothesized lexicographic definitions. By hypothesized lexicographic definition, we mean that one does not need to formulate in writing a complete lexicographic definition (though, it is always preferable to do so) in order to gather enough semantic information about a given lexical unit. A teacher in class, for instance, should be able to mentally "draft" almost instantly a definition of a lexical unit in order to address a student's question or propose an exercise. In the same vein, a trained lexicographer should be able to mentally draft definitions - for instance for $\operatorname{leg}(s)$ in (3a) vs. (3b) vs. (4) - that are rich and precise enough to establish preliminary diagnostics. Again, such semantic approximations, without their materialization in the form of bona fide definitions, is in no way satisfactory and can only be used as an intermediary stage in lexicography. However, definition drafting can be done, 
the technique can be learned, and it does have useful applications if lexicographic abilities are not only applicable in the context of the theoretical lexicography, where one can be satisfied with spending weeks on perfecting the definition of a single lexical unit.

Additionally, it is possible to question the fact that the proper definition of a derived copolyseme, such as leg in (4) above, can be achieved without a preliminary hypothesis on the kind of relation it entertains with its lexical source, legs in (3a). It is not because we finalize complete and exact definitions of legs [of a person] in (3a) and leg [of an object] in (4) that we "discover" a metaphorical relation between the two. It is right the opposite: we postulate and want to account for a perceived metaphorical link, and this leads us to propose lexicographic definitions that do the job. After all, in the case of metaphor, as well as with many other copolysemy relations, encoding the semantic bridge is seldom a necessity if the goal is only to account for the type of referents the lexical unit we define may have in speech. We do it because we believe it has something to do with how the lexicon is structured. For instance, both $\operatorname{leg}(s)$ in (3a) and (4) share the collocate strong to mean 'that has the ability to function as it should' and we feel that this is not a mere coincidence, but somehow the consequence of a metaphorical transfer of combinatorial properties.

(6) a. Strong legs are important in all aspects of cheerleading, from stunts to gymnastics.

b. The heavy marble must be supported by strong legs, so the legs of this table are made offorged iron.

To conclude, the approach to polysemy presented here can be characterized as follows:

- it is postulated that polysemy of vocables, not monosemy, is the norm;

- polysemy should be modeled based on the description of copolysemy relations between senses that make up the corresponding vocable's polysemy structure (Section 2 below);

- the study of copolysemy relations is conducted inductively through lexicographic analysis;

- a postulated copolysemy relation between two lexical units is, in most standard cases, based on a postulated semantic bridge or other more indirect connection ${ }^{13}$ between the lexicographic definitions of these lexical units;

- it can be sufficient as a first step, for a trained lexicographer, to (mentally) draft such lexicographic definitions in order to postulate a semantic relation.

As mentioned earlier, using lexicographic definitions as basic modeling tools for polysemy is in accordance with the methodology of Natural Semantic Metalanguage: "In a system of semantic analysis based on a finite set of indefinables and on the principle of reductive paraphrase, meanings re-emerge as discrete, determinate entities, and the "riddle of polysemy" ceases to seem insoluble" (Wierzbicka 1996: 244). Two major methodological differences between what is proposed here and Natural Semantic Meta-

13 The Coderivation copolysemy relation introduced in Subsection 3.4.3 below is a case of indirect connection between copolysemes. 
language should, however, be stressed: (i) it is doubtful that Natural Semantic Metalanguage practitioners would agree with the systematic recourse to drafted definitions; (ii) their lexicographic definitions are not designed to explicitly explain copolysemy relations and there is no "cross-fertilization" of copolysemes' definitions (Wierzbicka 1996: 269 - 270). On this latter point, we believe cross-fertilization can be a necessity, at least in such cases as metonymies and metaphors, for instance. Wierzbicka (1996)'s requirement that each definition should "stand alone" holds in the context of Natural Semantic Metalanguage, where the leading principle in defining is maximal decomposition of meanings based on the use of semantic primitives ${ }^{14}$. Within Explanatory Combinatorial Lexicology, where minimal instead of maximal decomposition is postulated (Mel'čuk 1989), cross-fertilization is inevitable and is, even, a necessity: for instance, neck [of a shirt, dress ... ] will necessarily be defined in terms of neck [of a person].

We now proceed, in Section 2, with the presentation of our methodology for studying polysemy in the context of the lexicographic construction of the French Lexical Network.

\section{LEXICOGRAPHIC MODELING OF POLYSEMY STRUCTURES}

We introduce our lexicographic approach to polysemy modeling in two steps. Firstly (2.1), we briefly summarize the theoretical and methodological principles on which the lexicographic project of the French Lexical Network is based, highlighting its main characteristics which distinguish it from more traditional products of Explanatory Combinatorial Lexicography: namely, Explanatory Combinatorial Dictionaries (Mel'čuk and Zholkovsky 1984, Mel'čuk et al. 1984-1999). Secondly (2.2), we focus on the notion of polysemy structure of vocables and on its encoding in the French Lexical Network.

\subsection{The French Lexical Network (fr-LN) Project}

The present study targets a deepening of the notion of polysemy through descriptive practice. As mentioned at the very beginning of the paper, this research is anchored in Explanatory Combinatorial Lexicology (Mel'čuk et al. 1995), from which it borrows most of it theoretical notions and descriptive principles. The most significant difference in the study presented here and "classical" Explanatory Combinatorial Lexicology is that it is based on a new form of lexicography, namely the lexicography of Lexical Systems, presented in Polguère (2014). We cannot explain in detail the characteristics of this lexicographic practice, and we concentrate on a brief presentation of the lexicographic models it produces: Lexical Systems.

Lexical Systems are network models of natural languages lexicons - i.e. unlike dictionaries, they are non-linear and non-textual. They were first presented

14 As has been rightfully pointed out to us by one of the anonymous reviewers of this paper, this statement is no longer entirely true since semantic molecules have been introduced in Natural Semantic Metalanguage. They are indeed convenient tools in the approach for implementing definition crossfertilization. See, for instance, Goddard (2011: 377-378)'s definition of 'head 2' [of an animal] in terms of 'head $\mathbf{1}$ [of a person]', which has the status of semantic molecule in the definitional metalanguage. 
in Polguère (2009), based on an experiment in automatically compiling a dictionary-like Explanatory Combinatorial lexical database for French into a network structure closer to what we expect is a plausible representation of the organization of the logical mental lexicon (Polguère 2016b) ${ }^{15}$. Since then, the notion of Lexical System has been refined through large-scale lexicographic work centered mainly around the construction of the first handmade Lexical System: the French Lexical Network, hereafter fr-LN (Lux-Pogodalla and Polguère 2011).

A Lexical System of a given language, such as the fr-LN, is formally a huge graph whose nodes are in most cases lexical units of the language (lexemes and idioms) and whose arcs are in most cases paradigmatic and syntagmatic relations that connect these lexical units. The bulk of the graph structuring of Lexical Systems, in terms of lexical node connections, relies on the system of Meaning-Text standard lexical functions (Mel'čuk 1996, 2007): paradigmatic lexical functions corresponding to semantic derivatives of lexical units - Syn, Anti, Conv $\mathbf{v}_{i j}, \mathbf{S}_{\mathbf{i}} \ldots$ - and syntagmatic lexical functions corresponding to collocations controlled by lexical units — Magn, Ver, Bon, oper ${ }_{1} \ldots^{16}$

The graph that makes up a Lexical System is a non-taxonomic structure, unlike the graph of well-known lexical networks such as WordNet (Fellbaum 1998) and BabelNet (Navigli and Ponzetto 2012). A Lexical System graph closely resembles, in terms of global structuring, common social networks - e.g. the graph of "friend" connections in Facebook. This type of information structure is called small-world network (Watts and Strogatz 1998) and it possesses specific topological characteristics which make it particularly suitable for such operations as automatic node clustering and analogical reasoning.

At present, lexicographic work focuses on Lexical Systems for three languages: French - the fr-LN, on which the present study is based —, Russian (Krylosova 2017) and English (Gader et al. 2014). Small samples have also been constructed for Arabic, Italian, Korean and Spanish.

The main change introduced in Explanatory Combinatorial Lexicology by the use of Lexical Systems as structural models of lexicons - as opposed to "textual" dictionaries - is that each lexical unit in this approach is first and foremost characterized by its lexical cluster (see 3.1 below): the micro-system of paradigmatic and syntagmatic relations the lexical unit is at the center of. Within the framework of Lexical System lexicography, the lexical cluster of each lexical unit is systematically taken

15 Polguère (2016b) establishes a distinction between two notions of mental lexicon: the physiological mental lexicon - the lexicon as information stored in the brain of individual speakers vs. the logical mental lexicon - the lexicon as main structural component of langue in the Saussurian sense. The physiological mental lexicon is the object of study in such disciplines as neurolinguistics and its structuring is in great part constrained by human physiology. The logical mental lexicon is the true object of study in lexicology. Its organization follows mathematical and logical principles while being structurally compatible with (though radically distinct from) the physiological mental lexicon. For a discussion of a cognitive-based approach to the modeling of polysemy, see Zalizniak (2007).

${ }^{16}$ A brief but informative introduction to lexical functions - with a list of simple standard lexical functions - can be found in the English Wikipedia entry for the notion: https://en.wikipedia.org/ wiki/Lexical_function [consulted on July 31, 2018]. 
into consideration while interpreting linguistic data and making decision on how to model them. This methodological aspect of the work will very clearly manifest itself in the remainder of the paper.

We cannot delve further into the topic of Lexical Systems and their lexicographic construction for lack of space. In next subsection, we concentrate on how polysemy structures of vocables are modeled in Lexical Systems and, in particular, in the fr-LN.

\subsection{Polysemy Structure of Vocables in the fr-LN}

Standard dictionaries describe vocables' polysemy following what has been termed the enumerative approach (Falkum and Vicente 2015: 3-5): one by which all senses of a given vocable are listed in its dictionary entry with minimal information (if any) to reflect its actual polysemic organization. Structural information on polysemy takes mainly the form of lexicographic numbering, symbols (bullets, punctuation signs ...) and sense labels such as Figur(ative), By extension, etc., which are supposed to reflect some form of internal hierarchical organization of the vocable ${ }^{17}$.

Sense enumeration is the lexicographic dead horse that everybody seems to love to flog, especially when it comes to justify a refusal to undertake the painstaking and endless endeavor of describing lexical polysemy. We believe in a more constructive attitude. The approach adopted in describing French polysemy in the fr-LN is non-enumerative as senses are not simply listed, or collected, in the lexical network: they are explicitly connected by a set of clearly identified $\mathrm{L}_{1} \rightarrow \mathrm{L}_{2}$ copolysemy relations (Subsection 1.3.1 above). The result is a tree-like hierarchical structure, such as the one given in Figure 1 below for the French vocable $\mathrm{JAMBE}^{18}$.

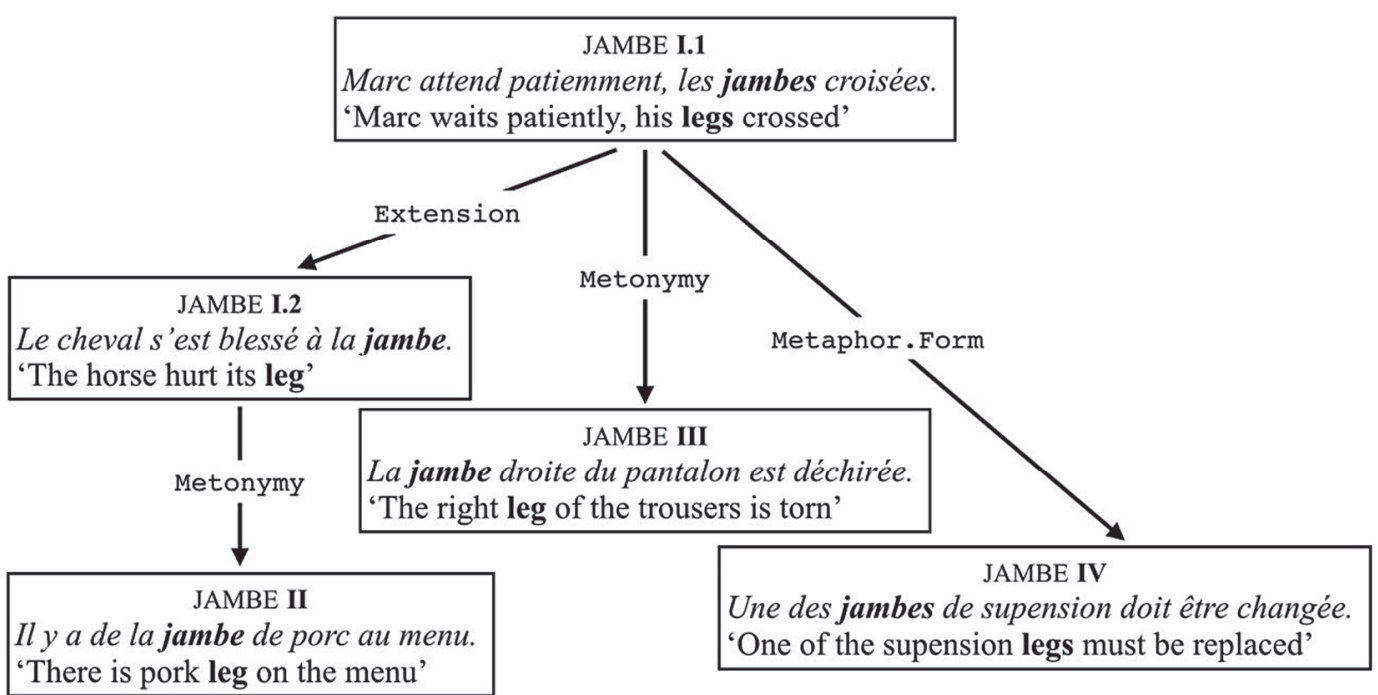

Figure 1. Polysemy structure of the French vocable JAMBE in the fr-LN

${ }^{17}$ Figurative means that sense $\mathrm{L}_{2}$ in the vocable's entry is figurative relative to sense $\mathrm{L}_{1}$; By extension means that $\mathrm{L}_{2}$ is a semantic extension of $\mathrm{L}_{1}$; etc.

18 All polysemy relations appearing in Figures 1 and 2 are explained in detail in Section 3 below. 
Though polysemy structures of vocables are by default acyclic graphs (i.e. trees), such as in Figure 1 above, they may exceptionally contain cycles, where one sense appears as direct copolyseme of more than just one other sense. This is a consequence of the fact that, from a strict theoretical viewpoint, nothing forbids a sense to be synchronically derived from several other senses. For instance, a sense can be simultaneously a form-based metaphor copolyseme and a function-based metaphor of another copolyseme, though this kind of configuration can be expected to be very rare. An example can be found in the fr-LN with the vocable TAILLE ${ }^{2}$, whose polysemy structure is visualized in Figure $2^{19}$.

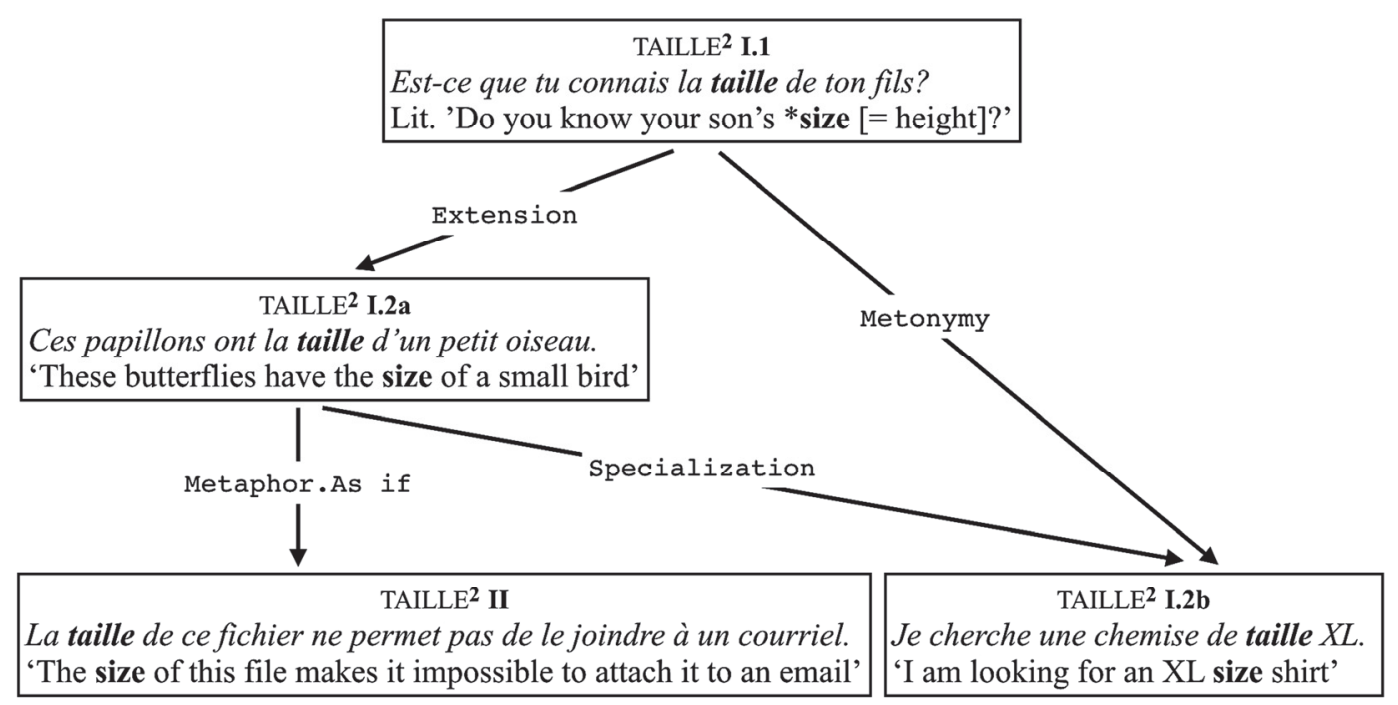

Figure 2. Polysemy structure of the French vocable TAILLE ${ }^{2}$ in the fr-LN

The collection of all copolysemy relations weaved in the fr-LN makes an important contribution to the overall relational structuring of this Lexical System, together with lexical function relations. At the moment of writing, the fr-LN contains 8,890 copolysemy relations against 59,336 paradigmatic and syntagmatic lexical function relations; all these relations connect 28,353 lexical nodes, grouped into 18,196 vocables ${ }^{20}$. The system of copolysemy relations identified in the fr-LN corresponds to only part of the polysemy of the French language; it is, however, significant enough to be considered as being far beyond the stage of sampling. To our knowledge, the fr-LN is the only network-like model of a natural language lexicon that embeds such an extensive and explicit description of copolysemy relations.

Now that the general lexicographic principles underlying our approach to polysemy modeling have been introduced, we can proceed with the description of copolysemy relations identified through lexicographic construction of the fr-LN.

19 The superscript number in the name of the vocable TAILLE ${ }^{2}$ is an indication of the fact that there is a TAILLE ${ }^{1}$ homonym in the fr-LN.

${ }^{20}$ The fr-LN is freely distributed through the ORTOLANG platform (https://www.ortolang.fr). Contact should be made directly with us for up-to-date versions of the database. 


\section{COPOLYSEMY RELATIONS IDENTIFIED IN THE fr-LN}

\subsection{General Picture}

We explained in some detail earlier (Subsection 1.4.2) that the key to the identification and characterization of copolysemy relations $\mathrm{L}_{1} \rightarrow \mathrm{L}_{2}$ is the comparison of (drafted or hypothesized) lexicographic definitions for both $\mathrm{L}_{1}$ and $\mathrm{L}_{2}$. In that sense, the name of each given copolysemy relation we have identified is, first of all, a representation of the ratio between the meaning ' $\mathrm{L}_{1}$ ' and the meaning ' $\mathrm{L}_{2}$ '. However, it has also been noted in Subsection 2.1 that, beside $\mathrm{L}_{1}$ and $\mathrm{L}_{2}$ 's lexicographic definitions, another fundamental parameter is taken into consideration in the context of the lexicography of Lexical Systems: $\mathrm{L}_{1}$ and $\mathrm{L}_{2}$ 's lexical clusters.

Definition 6. The lexical cluster of a lexical unit is the system of paradigmatic and syntagmatic relations it controls and that positions this lexical unit within the topology of the lexical graph of the language.

The lexical cluster of a given lexical unit acts as its fingerprint within the Lexical System of the language and represents a significant proportion of the differentiating lexicographic information (cf. 1.4.1 above) to be examined when comparing two copolysemes. Each lexical unit can be considered from the viewpoint of either its semantic lexical cluster or semantic space (Polguère 2014: 11-12) - the system of semantically relevant relations that connects it to other lexical units - or its full lexical cluster - the system of all relations, including semantically empty ones (e.g. purely formal ones), that connects it to other lexical units.

The crucial notion of lexical cluster being introduced, we can proceed with the presentation of copolysemy relations. All copolysemy relations that have been identified in the fr-LN until now are listed in Table 1 below according to four descriptive parameters (the table's four columns).

1. Weight. The (semantic) weight of a copolysemy relation indicates to what extent this relation can participate in structuring the semantic lexical cluster of individual lexical units. We conceptualize the weight as a measurement of the semantic cohesiveness of copolysemy relations within the lexical network of the language. The weight can take three values, from the highest to the lowest degree of cohesiveness: Tight, Loose and Non-cohesive. (Copolysemy relations are listed in this order in Table 1.) To illustrate the notion of semantic weight of copolysemy relations, let us contrast Metonymy and Metaphor. Metonymy is a tight relation because the two copolysemes it connects belong to the same semantic space or to two closely related semantic spaces: e.g., by virtue of their definitions, NECK I [of a person] and NECK II [of a shirt] must have intersecting semantic lexical clusters. By contrast, Metaphor is a noncohesive relation with respect to semantic space: there is no reason to expect NECK I [of a person] and NECK III [of a bottle] to have intersecting semantic lexical clusters.

2. Type. The type of a copolysemy relation is the central (and often unique) element of its denomination. Types (or names) of copolysemy relations are systematically written with an initial capital letter and formatted in a non-proportional font in order 
to clearly distinguish them from various notions that may exist in linguistics. For instance, Metaphor designates a copolysemy relation in our model and not the rhetorical figure of metaphor. The same kind of remark applies to Conversion, Causation, etc.

3. Subtype. Some polysemy relation types are too general to allow for a description with sufficient level of granularity, even at this initial stage of elaboration of our model. In such cases, a subtype (or sub-name) is provided. The subtypes that appear in bold in Table 1 are compulsory.

4. Derivation. For each copolysemy relation $\mathrm{L}_{1} \rightarrow \mathrm{L}_{2}$, it is specified in Table 1 whether this relation corresponds to a true polysemy derivation or not, i.e. whether the meaning of $\mathrm{L}_{2}$ can be considered as being derived from the meaning of $\mathrm{L}_{1}$. Only three copolysemy relations are not actual polysemy derivations: Intersection, Grammaticalization and Coderivation. This means that, for such relations, we do not expect the lexicographic definitions of both lexical units to directly reflect their connection as copolysemes, and this will be explained for each individual relation in Subsections 3.2 to 3.4. We are fully aware though that the very notion of polysemy derivation would call for some in-depth discussion, that we cannot undertake here - see, for instance, the discussion of the distinction between deductibily and motivatedness in Zalizniak (2007).

Table 1

Copolysemy relations in the French Lexical Network (fr-LN)

\begin{tabular}{|c|c|c|c|}
\hline Weight & Type & Subtype & Derivation \\
\hline Tight & Conversion & & Yes \\
\hline Tight & Causation & & Yes \\
\hline Tight & Result & & Yes \\
\hline Tight & Specialization & Subsense & Yes \\
\hline Tight & Generalization & & Yes \\
\hline Tight & Metonymy & Set of, Part of & Yes \\
\hline Loose & Extension & & Yes \\
\hline Loose & Antiphrasis & & Yes \\
\hline Loose & Intersection & & No \\
\hline Non-cohesive & Metaphor & $\begin{array}{l}\text { As if, Meton as if, Behavior, Function, } \\
\text { Functioning, Form, Position, Structure, } \\
\text { Usage }\end{array}$ & Yes \\
\hline Non-cohesive & Grammaticalization & & No \\
\hline Non-cohesive & Coderivation & & No \\
\hline
\end{tabular}

Each copolysemy relation listed in Table 1 is described in Subsections 3.2 to 3.4 according to the following pattern:

- general characterization of the relation;

- illustration borrowed from the fr-LN - therefore, from the French language;

- additional comments - these comments are often minimal, due to lack of space, and are detailed only when it appears to be absolutely required. 
Note that the illustration of a given $\mathrm{L}_{1} \rightarrow \mathrm{L}_{2}$ relation in presented in a table that has the following structure:

\begin{tabular}{|l|l|l|}
\hline$L_{1}$ & $<$ Lexicographic name of $L_{1}>$ & $\begin{array}{l}<\text { Short French example of use of } L_{1}> \\
<\text { English translation of the example }>\end{array}$ \\
\hline$L_{2}$ & $<$ Lexicographic name of $L_{2}>$ & $\begin{array}{l}<\text { Short French example of use of } L_{2}> \\
<\text { English translation of the example> }\end{array}$ \\
\hline
\end{tabular}

English translations of examples for $\mathrm{L}_{2}$ are either "valid" translations, when the same corresponding $\mathrm{L}_{1} \rightarrow \mathrm{L}_{2}$ copolysemy exists in English (e.g. illustration table in Subsection 3.2.1 below), or literal with the indication of the correct lexical equivalent for $\mathrm{L}_{2}$ between square brackets, when the corresponding copolysemy is absent from English (e.g. illustration table in Subsection 3.2.3).

When characterizing copolysemy relations, we often make use of the notion of denotation of a lexical unit. It can be defined as follows.

Definition 7. The denotation of a lexical unit is the (potentially infinite) set of facts or entities this lexical unit can designate strictly as function of its meaning.

Note that some lexical units do not have a denotation because they do not possess a meaning that allows for the designation of facts or entities; such is the case of auxiliary verbs or purely structural prepositions, such as of in to think of something.

Subsections 3.2 to 3.4 below present copolysemy relations in three groups, according to their cohesiveness (i.e. their semantic weight). This presentation is inevitably a bit enumerative as it accounts for preliminary results of an inductive approach to the identification of copolysemy relations. Much work remains to be done on testing the validity of the description before an actual theorization of copolysemy relations can be elaborated and before a better mode of presentation can be found.

\subsection{Tight Copolysemy Relations}

Tight $\mathrm{L}_{1} \rightarrow \mathrm{L}_{2}$ relations are characterized by the fact that $\mathrm{L}_{2}$ possesses roughly the same denotation as $\mathrm{L}_{1}$ - Conversion - , a narrower or broader denotation Causation, Result, Specialization, Generalization - or a somehow "orthogonal" denotation - Metonymy.

In terms of network structuring of the lexicon, if $\mathrm{L}_{2}$ is in a tight copolysemy relation with $\mathrm{L}_{1}$, its lexical cluster is almost identical to, or largely overlaps with $\mathrm{L}_{1}$ 's.

\subsubsection{Conversion}

An $\mathrm{L}_{1}$ Conversion $\rightarrow \mathrm{L}_{2}$ relation is such that $\mathrm{L}_{2}$ is an exact or approximate lexical conversive of $\mathrm{L}_{1}$ : it possesses (roughly) the same denotation as $\mathrm{L}_{1}$ but its active valency displays a permutation of $\mathrm{L}_{1}$ 's syntactic actants. For instance, in the fr-LN:

\begin{tabular}{|l|l|l|}
\hline $\mathrm{L}_{1}$ & COMMENCER I.2a & $\begin{array}{l}\text { Le roman commence par un meurtre. } \\
\text { 'The novel begins with a murder' }\end{array}$ \\
\hline $\mathrm{L}_{2}$ & COMMENCER I.2b & $\begin{array}{l}\text { Un meurtre commence le roman. } \\
\text { 'A murder begins the novel' }\end{array}$ \\
\hline
\end{tabular}


Conversion is a marginal copolysemy relation in the fr- $\mathrm{LN}$ - and probably in French and in most languages as well: it represents barely more than $0.5 \%$ of the relations currently encoded in the fr-LN.

Note that Conversion possesses a counterpart among Meaning-Text paradigmatic lexical functions, namely Conv $_{j i}$. The relationship that some copolysemy relations entertain with paradigmatic or syntagmatic lexical functions is clearly an important topic, which calls for further study.

\subsubsection{Causation}

An $\mathrm{L}_{1}$ Causation $\rightarrow \mathrm{L}_{2}$ relation is such that $\mathrm{L}_{2}$ means approximately 'to cause $<$ cause of $>\mathrm{L}_{1}$ '. In the fr-LN:

\begin{tabular}{|l|l|l|}
\hline$L_{1}$ & APPRENDRE I.1 & $\begin{array}{l}\text { Elle apprend la boxe. } \\
\text { 'She learns boxing' }\end{array}$ \\
\hline$L_{2}$ & APPRENDRE I.2 & $\begin{array}{l}\text { Je lui apprends la boxe. } \\
\text { 'I teach her boxing' }\end{array}$ \\
\hline
\end{tabular}

Causation has Caus as syntagmatic lexical function counterpart and is directly related to the next copolysemy relation: Result.

\subsubsection{Result}

An $L_{1}$ Result $\rightarrow L_{2}$ relation is such that the denotation of $L_{2}$ is a set of facts or entities that can be considered as being prototypical results of the facts that make up the denotation of $\mathrm{L}_{1}$. Semantically, $\mathrm{L}_{2}$ is the de-causative counterpart of $\mathrm{L}_{1}$; Causation, above, and Result are therefore symmetrical. In the fr-LN:

\begin{tabular}{|l|l|l|}
\hline $\mathrm{L}_{1}$ & HUMILIATION 1 & $\begin{array}{l}\text { Comment peut-il supporter les humiliations infligées par son patron? } \\
\text { 'How can he cope with humiliations inflicted by his boss?' }\end{array}$ \\
\hline $\mathrm{L}_{2}$ & HUMILIATION 2 & $\begin{array}{l}\text { Nous ressentons une profonde humiliation. } \\
\text { 'We feel a deep humiliation' }\end{array}$ \\
\hline
\end{tabular}

Both Causation and Result are weakly present in the fr-LN: not even $1 \%$ each. Note that Causation and Result may be exceptionally rare for verbs in the fr-LN as French possesses de-causative reflexive verbs - e.g. DISSOUDRE ' $\mathrm{X}$ dissolves $\mathrm{Y}$ in $\mathrm{Z}$ ' vs. SE DISSOUDRE ' $Y$ dissolves in $Z$ '. The reflexive counterpart of a non-reflexive verb is considered to belong to a separate vocable; therefore, the relation between the two verbs cannot be one of copolysemy.

Result has two paradigmatic lexical function counterparts, either $\mathbf{S}_{\text {res }}$ or Resul $t_{i}$, depending on the semantico-syntactic ratio between $L_{1}$ and $L_{2}$. In the above example, HUMILIATION 2 is an $\mathbf{S}_{\text {res }}$ for HUMILIATION $\mathbf{1}$. Below, SALIR $\mathbf{2}$ is a Result 2 for SALIR 1:

\begin{tabular}{|l|l|l|}
\hline $\mathrm{L}_{1}$ & SALIR 1 & $\begin{array}{l}\text { Elle a sali sa chemise avec de la sauce tomate. } \\
\text { 'She dirtied her shirt with tomato sauce' }\end{array}$ \\
\hline $\mathrm{L}_{2}$ & SALIR 2 & $\begin{array}{l}\text { Elle frotte la sauce tomate qui salit sa chemise. } \\
\text { Lit. 'She rubs the tomato sauce that *dirties [= stains] her shirt' }\end{array}$ \\
\hline
\end{tabular}




\subsubsection{Specialization}

An $L_{1}$ Specialization $\rightarrow L_{2}$ relation is such that $L_{2}$ is a richer synonym of $L_{1}$, $\mathrm{cf}$. the Syn lexical function, or at least contains $\mathrm{L}_{1}$ as central (generic) component of its definition. In the fr-LN:

\begin{tabular}{|l|l|l|}
\hline $\mathrm{L}_{1}$ & BAGUETTE I.1 & $\begin{array}{l}\text { Elle a utilisé des baguettes de bois pour fabriquer un cheval miniature. } \\
\text { 'She used wooden sticks to make a miniature horse' }\end{array}$ \\
\hline $\mathrm{L}_{2}$ & BAGUETTE I.2a & $\begin{array}{l}\text { Elle mange son riz avec des baguettes. } \\
\text { Lit. 'She eats her rice with *sticks [= chopsticks]' }\end{array}$ \\
\hline
\end{tabular}

Specialization is not common in the fr-LN: less than $2.5 \%$. It is directly related to the even less common Generalization relation (Subsection 3.2.5 below).

There exists a special subtype of Specialization that we termed Subsense, following Cruse (1995: 39-40). In an $\mathrm{L}_{1}$ Specialization. Subsense $\rightarrow \mathrm{L}_{2}$ relation, $\mathrm{L}_{2}$ possesses the exact same denotation as $\mathrm{L}_{1}$ except for parameters linked to a specific domain of functioning, usage, etc. In the fr-LN:

\begin{tabular}{|l|l|l|}
\hline $\mathrm{L}_{1}$ & ABEILLE I.a & $\begin{array}{l}\text { Elle étudie les abeilles, les guêpes, les fourmis et autres insectes sociaux. } \\
\text { 'She studies bees, wasps, ants and other social insects' }\end{array}$ \\
\hline $\mathrm{L}_{2}$ & ABEILLE I.b & $\begin{array}{l}\text { Administrativement, l'élevage des abeilles relève des activités agricoles. } \\
\text { 'Administratively, raising bees falls within agricultural activities' }\end{array}$ \\
\hline
\end{tabular}

Clearly, Specialization. Subsense is a very borderline case of copolysemy, one where $\mathrm{L}_{2}$ is not a distinctly separate lexical unit from $\mathrm{L}_{1}$. All lexical information associated to $\mathrm{L}_{1}$ is also associated to $\mathrm{L}_{2}$ : $\mathrm{L}_{2}$, as a lexical unit, is $\mathrm{L}_{1}$ "from a given viewpoint". However, the converse is not true. $\mathrm{L}_{2}$, because it is associated with a specific domain, controls a much richer lexical cluster than $\mathrm{L}_{1}$. In point of fact, the same $\mathrm{L}_{1}$ can have multiple $\mathrm{L}_{2}$ subsenses, each one of them controlling its own specific lexical cluster ${ }^{21}$.

Because they are borderline cases, subsenses are often used in the literature when debating such existential questions as: Does polysemy really exist?; Can it be systematically handled?; Do dictionaries over-generate senses in their entries? A good illustration of this is the case of the English vocable $\operatorname{LOVE}_{(\mathrm{V})}$ - together with $\operatorname{LOVE}_{(\mathrm{N})}$ discussed by Goddard (2011: 40-42) in the context of his criticism of the proliferation of polysemy in dictionaries ${ }^{22}$. The central question Goddard examines is the distinction made by most dictionaries between a sex-free and a sex-related sense of $\operatorname{LOVE}_{(\mathrm{V} / \mathrm{N})}$. Goddard's claim is that it is impossible to circumscribe everything that can go with love and that love can take multiple forms and manifestations. Consequently, he proposes

${ }^{21}$ The English vocable KNIFE is a classic example for such copolysemy configuration. Its basic lexical unit is connected to a series of subsenses; at least: 'knife as a weapon', 'knife as a kitchen instrument' and 'knife as tableware'.

22 "Although lexical polysemy is a fact of life, dictionaries generally speaking posit excessive polysemy” (Goddard 2011: 40). 
a Natural Semantic Metalanguage explanation for one single sense of $\operatorname{LOVE}_{(\mathrm{V})}$, that is supposed to encompass all forms of love:

"Someone $X$ loves someone $Y$ : $\mathrm{X}$ feels something good towards $\mathrm{Y}$, thinks good things about $\mathrm{Y}$, wants to do good things for $\mathrm{Y}$, and wants good things to happen to Y" (Goddard 2011:41)

If this is the definition for a one and unique sense of $\operatorname{LOVE}_{(\mathrm{V})}$, our main problem with it is: but where is the sex? There exist in the English language many traces of a lexicalization of the love-sex association; e.g. idioms such as MAKE LOVE or LOVE MAKING, and the separate sense of $\operatorname{LOVE}_{(\mathrm{N})}$ that means 'love making' and that has to be derived from another sense containing 'sexual desire' in its definition:

(7) Was there a need for the rest after love?

The problem with Goddard's argument is that it is based on a purely conceptual reasoning, which can lead lexicographers either way. If we look at the lexical cluster of $\operatorname{LOVE}_{(\mathrm{V} / \mathrm{N})}$ in the English lexicon, on the other hand, and if we want to account for it in a simple manner, there is no other solution but to postulate a specialized sense of $\operatorname{LOVE}_{(\mathrm{V} / \mathrm{N})}$, one that is a subsense (= a manifestation) of the more neutral basic sense and is at the center of a very specific network of lexical relations (lover, in love, puppy love, platonic love, etc.). It is mainly this systemic positioning in the global lexical network of English that gives this subsense a relative autonomy and, hence, a true existence in the English language. If this lexical cluster were not present in English, on the other hand, we would fully agree that there is no need to consider a separate sense.

We have discussed at length Specialization. Subsense because we believe that this apparently marginal relation plays in reality a crucial role in the development and structuring of the lexicon as regards to specialized vocabularies (i.e. terminologies). It often comes into play in association with technical/scientific terms that are inextricably embedded within general language - see, e.g., $\mathrm{BOND}_{(\mathrm{N})}$ as a general language lexical unit $v s$. as a chemistry term (Ingrosso and Polguère 2015).

\subsubsection{Generalization}

An $L_{1}$ Generalization $\rightarrow L_{2}$ relation is such that $L_{2}$ is a poorer synonym of $\mathrm{L}_{1}$, cf. the $\mathrm{Syn}_{\subset}$ lexical function; its definition is identical to that of $\mathrm{L}_{1}$ except for some missing components. In the fr-LN:

\begin{tabular}{|l|l|l|}
\hline $\mathrm{L}_{1}$ & CHAMP $^{1} \mathrm{I} .1$ & $\begin{array}{l}\text { Les paysans labourent les champs. } \\
\text { 'Farmers are plowing the fields [= piece of land for growing crop]' }\end{array}$ \\
\hline $\mathrm{L}_{2}$ & CHAMP $^{1} \mathrm{I.2}$ & $\begin{array}{l}\text { Les vaches sont déjà au champ. } \\
\text { 'Cows are already in the field [= piece of agricultural land]' }\end{array}$ \\
\hline
\end{tabular}

Generalization is extremely marginal: only three occurrences in the fr-LN. Additionally, all cases we have identified are somehow controversial. For instance, the second sense of CHAMP above, CHAMP $^{1}$ I.2, could be fused with the first one, from 
the strict point of view of its definition. The reason we keep both senses separated is that CHAMP ${ }^{1}$ I.1 - 'open land for growing crops' - controls a very specific lexical cluster that simply does not apply to the more general CHAMP ${ }^{1}$ I.2. But again, our analysis of the polysemy structure of champ in the fr- $\mathrm{LN}$ is debatable and it is safe to say that Generalization is more a logically plausible copolysemy relation than a truly attested one ${ }^{23}$.

\subsubsection{Metonymy}

An $\mathrm{L}_{1}$ Metonymy $\rightarrow \mathrm{L}_{2}$ relation is such that the denotation of $\mathrm{L}_{2}$ relates to the denotation of $\mathrm{L}_{1}$ through contiguity, in the broadest sense of the term. As a consequence, the meaning ' $\mathrm{L}_{1}$ ' necessarily appears in the lexicographic definition of $\mathrm{L}_{2}$, though not as central component. In the fr-LN:

\begin{tabular}{|l|l|l|}
\hline $\mathrm{L}_{1}$ & RAISIN a & $\begin{array}{l}\text { Notre raisin est récolté à la main. } \\
\text { 'Our grape is harvested by hand' }\end{array}$ \\
\hline $\mathrm{L}_{2}$ & RAISIN b & $\begin{array}{l}\text { Décorez votre salade avec quelques raisins [= grains de raisin a]. } \\
\text { 'Decorate your salad with a few grapes [= grape berries]' }\end{array}$ \\
\hline
\end{tabular}

Metonymy is the first copolysemy relation examined here that is truly widespread in the fr-LN - $18 \%$ of all relations - and most probably in the lexicon of all natural languages as well. Metonymy, as characterized above by the very general notion of contiguity (whether physical, temporal, psychological, logical, etc.), is a heterogenous phenomenon. A complete modeling of Metonymy relations calls for a sub-classification of these relations. As indicated in Table 1 (Subsection 3.1 above), we have for now introduced only two subtypes of Metonymy: Set of and Part of. As our descriptive apparatus is still embryonic, the indication of a subtype is not obligatory for the time being when encoding Metonymy relations. In the future, all our currently encoded relations should be carefully analyzed in order to identify and encode new subtypes, so that all cases of Metonymy relations are made more specific.

\subsection{Loose Copolysemy Relations}

Loose $\mathrm{L}_{1} \rightarrow \mathrm{L}_{2}$ relations are characterized by the fact that lexicographic definitions of $\mathrm{L}_{1}$ and $\mathrm{L}_{2}$ share significant semantic content without having directly related denotation - contrary to all cases of tight copolysemy relations we just examined.

In terms of network structuring of the lexicon, if $\mathrm{L}_{2}$ is in a loose copolysemy relation with $\mathrm{L}_{1}$, its lexical cluster marginally intersects with $\mathrm{L}_{1}$ 's, as opposed to cases of tight copolysemy relations (Subsection 3.2 above).

${ }^{23}$ Another legitimate question is why choosing the semantically more specific CHAMP I.1 over the more general CHAMP I.2 as origin of the copolysemy relation. We have no better answer to offer than the fact that the use of the latter by French speakers is rather marginal and it is a rather elusive lexical unit from a lexicographic point of view. 


\subsubsection{Extension}

An $\mathrm{L}_{1}$ Extension $\rightarrow \mathrm{L}_{2}$ relation is such that the denotation of $\mathrm{L}_{2}$ is relatively close to the denotation of $\mathrm{L}_{1}$ while it is clear that no (quasi-)synonymy relation holds between these two lexical units. It is as if the meaning ' $\mathrm{L}_{1}$ ' had been doctored in order to construct the meaning ' $\mathrm{L}_{2}$ '. In the fr- $\mathrm{LN}$ :

\begin{tabular}{|l|l|l|}
\hline $\mathrm{L}_{1}$ & GATEAU a & $\begin{array}{l}\text { Nous devons trouver des bougies pour le gâteau d'anniversaire. } \\
\text { 'We have to find candles for the birthday cake' }\end{array}$ \\
\hline $\mathrm{L}_{2}$ & GATEAU b & $\begin{array}{l}\text { Je prends un paquet de gâteaux au cas où on a faim dans l'après-midi. } \\
\text { Lit. 'I bring a pack of *cakes [= cookies] in case we feel hungry in the afternoon' }\end{array}$ \\
\hline
\end{tabular}

Note that in many instances - such as for the BRAS I.1a $v s$. BRAS I.3 pair presented below - an Extension relation could be argued to be in reality a Metaphor relation (Subsection 3.4.1 below).

\begin{tabular}{|l|l|l|}
\hline$L_{1}$ & BRAS I.1a & $\begin{array}{l}\text { Elle a failli se casser le bras en tombant dans l'escalier. } \\
\text { 'She almost broke her arm falling in the stairs' }\end{array}$ \\
\hline $\mathrm{L}_{2}$ & BRAS I.3 & $\begin{array}{l}\text { Les pieuvres possèdent huit bras munis de ventouses. } \\
\text { 'Octopuses have eight arms equipped with suckers' }\end{array}$ \\
\hline
\end{tabular}

One could say that octopus arms are called bras 'arms' in French by analogy, as if they were indeed (human) arms. As always in the lexical network approach to lexicology/lexicography, our decision will be guided, not by some form of purely conceptual/semantic reasoning, but rather by considering the individual cluster of each lexical unit. In this particular case, our perception is that BRAS I.3 controls a lexical cluster that is not sufficiently apart from the cluster controlled by BRAS I.1a to be considered as being a metaphor of BRAS I.1a: we will see in 3.4.1 below that the autonomy of the clusters controlled by the two copolysemes is a characteristic of a Metaphor relation.

Extension is a very common copolysemy relation in the fr-LN $-26.5 \%$ of all copolysemy relations. It can be considered as being the default relation among loose copolysemy relations within the fr-LN. At this stage, it would be adventurous to state that this is an actual characteristic of the polysemic organization of the French lexicon, or of the lexicon of natural languages in general. Much lexicographic work remains to be performed on the fr-LN - and undertaken on networks for other languages before we can venture to propose this type of theoretical generalization.

\subsubsection{Antiphrasis}

An $\mathrm{L}_{1}$ Antiphrasis $\rightarrow \mathrm{L}_{2}$ relation is such that the meaning of $\mathrm{L}_{2}$ is in a quasiantithetical relation with the meaning of $\mathrm{L}_{1}$. This relation generally entails an ironic stylistic charge in $\mathrm{L}_{2}$. In the fr-LN:

\begin{tabular}{|l|l|l|}
\hline $\mathrm{L}_{1}$ & JOYEUX I.1a & $\begin{array}{l}\text { Je vois des enfants joyeux qui jouent dans le parc. } \\
\text { 'I see cheerful children playing in the park' }\end{array}$ \\
\hline $\mathrm{L}_{2}$ & JOYEUX III & $\begin{array}{l}\text { Les enfants ont mis une joyeuse pagaille dans leur chambre. } \\
\text { Lit. 'Kids have made a *cheerful [= real nice }\end{array}$ \\
\hline
\end{tabular}


$\mathrm{L}_{1}$ Antiphrasis $\rightarrow \mathrm{L}_{2}$ was added quite recently to our list of copolysemy relations ${ }^{24}$ and it seems to be very marginal: only five cases identified so far in the fr-LN. It is our conjecture, however, that Antiphrasis may be more present in the polysemy of French than it appears to be as it is the lexicalized manifestation of a rhetorical figure commonly used in oral speech (Hénault 2008: 297).

\subsubsection{Intersection}

An $\mathrm{L}_{1}$ Intersection $\rightarrow \mathrm{L}_{2}$ relation is such that there is a perceived semantic relation between $\mathrm{L}_{1}$ and $\mathrm{L}_{2}$, but one that seems impossible to truly specify by contrasting these units' lexicographic definitions and by identifying a clear Extension, Metaphor, etc. relation. In other words, the term Intersection is used here to mean 'semantic intersection only, of undetermined nature'. The Intersection relation is therefore some kind of joker relation, for lack of a better characterization of the copolysemy relation under consideration. Because of the tenuous and synchronically unexplained nature of $\mathrm{L}_{1}$ Intersection $\rightarrow \mathrm{L}_{2}$ relations, $\mathrm{L}_{2}$ cannot be considered synchronically as being the product of an actual polysemy derivation. In the fr-LN:

\begin{tabular}{|l|l|l|}
\hline $\mathrm{L}_{1}$ & DISPOSER I & $\begin{array}{l}\text { Elle a disposé artistiquement des groseilles autour du gâteau. } \\
\text { 'She artistically placed red currants around the cake' }\end{array}$ \\
\hline $\mathrm{L}_{2}$ & DISPOSER II & $\begin{array}{l}\text { Paris dispose d'un réseau de métro extrêmement développé. } \\
\text { Lit. 'Paris *places [= possesses] an extremely developed underground network' }\end{array}$ \\
\hline
\end{tabular}

Intersection is rare in the fr-LN: less than $0.5 \%$ of all copolysemy relations. As can be seen with the above example, cases of $L_{1}$ Intersection $\rightarrow L_{2}$ relations are generally good candidates for homonymy rather than polysemy. It is only the intuitive perception by many native speakers of French of a semantic connection between DISPOSER I and DISPOSER II that justifies a non-homonymic description in this case $\mathrm{e}^{25}$.

It is not clear that the Intersection relation should be kept in the model and a simple drastic solution would be to have recourse to homonymy instead. In general, it is our opinion that there is nothing to gain and everything to lose by maintaining copolysemy links when they are not supported by clear evidence.

\subsection{Non-cohesive Copolysemy Relations}

Non-cohesive $\mathrm{L}_{1} \rightarrow \mathrm{L}_{2}$ relations are characterized by the fact that $\mathrm{L}_{2}$ 's denotation is, in principle, totally disconnected from that of $\mathrm{L}_{1}$. There are three types of such relations: Metaphor, Grammaticalization and Coderivation. For this latter case, note that two lexical units linked by a Coderivation relation could very well have intersecting denotations, but this would be purely coincidental and would not be a consequence of the characteristics of Coderivation as such (see 3.4.3 below).

In terms of network structuring of the lexicon, if $\mathrm{L}_{2}$ is in a non-cohesive copolysemy relation with $\mathrm{L}_{1}$, their lexical clusters can be expected to be largely distinct.

${ }^{24}$ We are grateful to Veronika Lux-Pogodalla for this.

25 The semantic connection, in this particular case, seems extremely tenuous: something like the vague semanteme 'presence [of something]'. This pair of lexemes may very well be treated as homonyms as well. 


\subsubsection{Metaphor}

An $\mathrm{L}_{1}$ Metaphor. $<$ Subtype $>\rightarrow \mathrm{L}_{2}$ relation is such that the denotation of $\mathrm{L}_{2}$ relates to the denotation of $\mathrm{L}_{1}$ through analogy in the broadest sense of the term. Metaphor is a heterogenous relation and compulsory subtypes have been introduced in the fr-LN model of copolysemy (Table 1, Subsection 3.1 above): As if, Meton as if, Behavior, Function, Functioning, Form, Position, Structure and Usage. For instance, the following $\mathrm{L}_{1} \rightarrow \mathrm{L}_{2}$ pair, borrowed from the fr-LN, illustrates a case of $\mathrm{L}_{1}$ Metaphor. Form $\rightarrow \mathrm{L}_{2}$ relation ${ }^{26}$.

\begin{tabular}{|l|l|l|}
\hline $\mathrm{L}_{1}$ & BAGUETTE I.1 & $\begin{array}{l}\text { Elle a utilisé des baguettes en bois pour fabriquer un cheval miniature. } \\
\text { 'She used wooden sticks to make a miniature horse' }\end{array}$ \\
\hline $\mathrm{L}_{2}$ & BAGUETTE II & $\begin{array}{l}\text { Elle a acheté deux baguettes au boulanger du coin. } \\
\text { Lit. 'She bought two *sticks [= baguettes] from the neighborhood bakery' }\end{array}$ \\
\hline
\end{tabular}

As if is the default subtype; it simply indicates the presence of at least one component in the definition of $\mathrm{L}_{2}$ which specifies the nature of the analogy that connects $\mathrm{L}_{1}$ and $\mathrm{L}_{2}$ 's denotations. As lexicographic work progresses and descriptions become finer, all occurrences of the As if subtype should be replaced with more specific subtypes. All other current subtypes are self-explanatory, except for Meton as if which we examine now.

In the course of weaving copolysemy relations in the fr-LN, we noticed the recurrent apparition of a very special type of metaphor: one that is rooted in an underlying metonymy and that we termed metonymy-based metaphor - cf. the Meton as if subtype. Let us explain this relation with an example borrowed from the fr-LN:

\begin{tabular}{|l|l|l|}
\hline $\mathrm{L}_{1}$ & BOIRE I.2a & $\begin{array}{l}\text { Désolé, je ne bois pas. } \\
\text { 'Sorry, I don't drink [= usually drink alcohol]' }\end{array}$ \\
\hline $\mathrm{L}_{2}$ & BOIRE II & $\begin{array}{l}\text { Chaque mois, il boit son salaire. } \\
\text { Lit. 'Each month, he *drinks [= drinks away] his salary' }\end{array}$ \\
\hline
\end{tabular}

Boire son salaire/ses économies/etc. (lit. 'to drink [= drink away] one's salary/ savings/etc.') is undoubtedly a metaphor. This sense of the vocable BOIRE is based on an analogy with BOIRE I.2a which means 'to have the habit of drinking (in the basic sense) alcohol'. However, the actual semantic connection between BOIRE I.2a and BOIRE II is quite complex as revealed by the following lexicographic definition of BOIRE II, written according to the principles of Explanatory Combinatorial Lexicology (Mel'čuk and Polguère In press).

\begin{tabular}{|l|l|}
\hline$X$ boit II $Y$ & $X$ gaspille $Y$ \\
'X drinks II Y' & 'X wastes $Y$ ' \\
& Y étant de l'argent \\
& 'Y being money' \\
& en dépensant $Y$ pour boire I.2.a de l'alcool de façon excessive \\
& 'by spending $Y$ on drinking I.2a alcohol in excess' \\
& comme si $Y$ était des boissons alcoolisées que $X$ boit I.2a \\
'as if $Y$ were alcoholic drinks that $X$ drinks I.2a'
\end{tabular}

26 Reminder: BAGUETTE I.1 is also used in Subsection 3.2.4 as the source of a Specialization copolysemy relation. 
The above definition clearly shows that the semanteme 'boire I.2a' is present twice in the definition of BOIRE II: first, outside the metaphoric component 'as if ...', in a component which explains that, in drinking II, there is indeed an act of drinking I.2a involved; second, in the metaphoric component 'as if ...', which explains that an act of drinking II Y presents an analogy with an act of drinking I.2a alcohol - in fact, it presents at the same time $Y$ (salary, savings, ...) as analogous to alcoholic drinks, i.e. something that can be drunk I.2a. The first occurrence of 'boire I.2a' implies that BOIRE II is, in part, in a metonymy relation with BOIRE I.2a (actual presence of an act of drinking I.2a on which the situation of drinking II is based). The second occurrence implies that BOIRE II is at the same time related to BOIRE I.2a by a relation of metaphor. With BOIRE II, we are faced with a clear case of metonymy-based metaphor.

To conclude on metonymy-based metaphors, it is important to highlight the fact that they are truly atypical in that they do not entail non-cohesive relations, as "normal" metaphors do: in an $\mathrm{L}_{1}$ Metaphor. Meton as if $\rightarrow \mathrm{L}_{2}$ relation, $\mathrm{L}_{2}$ is strongly connected to $\mathrm{L}_{1}$ from the viewpoint of their denotations because of the embedded metonymy.

Metaphor is by far the most widespread copolysemy relation in the fr-LN: over $48 \%$ of all such relations! This is an unexpected outcome of our study. We somehow anticipated some form of equilibrium between Metonymy, Extension and Metaphor relations, and were apparently wrong. A note of caution is, however, warranted before drawing any general conclusion about metaphor and polysemy. Most vocables of the fr-LN have been subjected to only a partial polysemy analysis. It is quite possible that, in the process of building polysemy structures, lexicographers tend to pick first metaphorical copolysemes because they are more easily identifiable and often "look good" in a vocable structure. We anticipate that the importance of Metaphor relations in the overall polysemy of the fr-LN will gradually decrease as polysemy structures of vocables receive finer descriptions. In order to test this hypothesis, we conducted a little experiment. The four published volumes of the Explanatory Combinatorial Dictionary of French (Mel'čuk et al. 1984-1999) describe quite exhaustively the polysemy of a representative sample of the French lexicon. By analyzing lexicographic definitions, we systematically identified metaphorical senses in the fourth volume of this dictionary, which contains 180 vocables for a total of 587 senses. Based on the principle that the number of copolysemy relations in a vocable structure is equal to the number of senses it contains minus 1 - because this structure is, by default, a tree graph,$-{ }^{27}$ we estimated the total number of copolysemy relations in the fourth volume of the dictionary to be $587-180=407$. As we identified 133 lexicographic definitions embedding a metaphorical component, we concluded that a bit less than $33 \%$ of copolysemy relations in this small but representative sample of the French lexicon are metaphors, against $48 \%$ in the fr-LN. Though it is by no means a demonstration of

27 The structure of a monosemous vocable is a minimal tree graph of only one node. The arithmetic for computing the number of copolysemy relations contained in its structure is therefore the same as for polysemous vocables: 1 sense minus 1 equals 0 copolysemy relation. 
the actual quantitative importance of Metaphor copolysemy relations in French, this experiment seems to corroborate our intuition that Metaphor is most probably overrepresented in the fr-LN in its current state.

\subsubsection{Grammaticalization}

An $\mathrm{L}_{1}$ Grammaticalization $\rightarrow \mathrm{L}_{2}$ relation is such that $\mathrm{L}_{2}$ is a grammatical or quasi-grammatical lexical unit that is (barely) related to $\mathrm{L}_{1}$ through extreme impoverishment of $\mathrm{L}_{1}$ 's meaning. It is only this perceived creation of $\mathrm{L}_{2}$ through semantic impoverishment from $\mathrm{L}_{1}$ that justifies considering a copolysemy relation instead of pure homonymy. Of course, Grammaticalization is a totally noncohesive relation and, additionally, $\mathrm{L}_{2}$ is not a copolysemy derivative of $\mathrm{L}_{1}$ in synchrony. There are two main cases of Grammaticalization, depending on the nature of $\mathrm{L}_{2}$.

Firstly, $\mathrm{L}_{2}$ can be a true grammatical lexical unit which participates in expressing either grammemes of the language (cf. auxiliary verbs) or syntactic dependencies (cf. valency-controlled empty prepositions such as in in to believe in something). In the fr-LN:

\begin{tabular}{|l|l|l|}
\hline $\mathrm{L}_{1}$ & AVOIR I.1 & $\begin{array}{l}\text { Elle } \text { a un ordinateur très bruyant. } \\
\text { 'She has a very noisy computer' }\end{array}$ \\
\hline $\mathrm{L}_{2}$ & AVOIR V.2 & $\begin{array}{l}\text { Elle a visité Barcelone. } \\
\text { 'She has visited Barcelona' }\end{array}$ \\
\hline
\end{tabular}

The French verb AVOIR possesses a very peculiar morphological behavior with unpredictable inflections ( $a v o i r_{\text {infinitive }}, e u_{\text {past part. }}, a i_{1 \text { st pers. sing. indic. pres. }}, \ldots$ ) that is identical for both AVOIR I.1 and AVOIR V.2. It is this formal identity, rather than any semantic consideration, that justifies the grouping of both lexical units within the same vocable. Otherwise, from a strictly semantic viewpoint, AVOIR I.1 and AVOIR V.2 could, and probably should be considered as homonyms.

Secondly, $\mathrm{L}_{2}$ can be a collocative lexical unit expressing the very basic and vague meaning of one of Meaning-Text lexical functions. Such is the case of the French support verb FAIRE II.1, which expresses the Oper ${ }_{1}$ lexical function.

\begin{tabular}{|l|l|l|}
\hline$L_{1}$ & FAIRE I & $\begin{array}{l}\text { Elle fait des crêpes. } \\
\text { 'She makes pancakes' }\end{array}$ \\
\hline$L_{2}$ & FAIRE II.1 & $\begin{array}{l}\text { Elle fait du yoga quotidiennement. } \\
\text { 'She makes some yoga daily' }\end{array}$ \\
\hline
\end{tabular}

Lexical units such as FAIRE II.1 are not true grammatical units, but their meaning is so poor - empty or close to empty in the case of support verbs - that their connection to their source copolyseme can be assimilated to Grammaticalization. A word of caution though: in order for a collocative lexical unit to be considered as linked through Grammaticalization to its source, it has to express the "bare" meaning of its corresponding lexical function. For instance, heavy in heavy sigh expresses the meaning of intensification - that is, of the Magn lexical function - and nothing more. Therefore, the corresponding collocative sense of the HEAVY vocable should be 
considered as connected through Grammaticalization to its source copolyseme. Contrary to this, verbs of realization - e.g. those corresponding to the Real $\mathrm{I}_{i}$ lexical function - are often standard full lexical units connected to their source copolyseme by a true polysemy derivation. For example, follow in to follow a lead in an inquiry a clear case of Real R $_{2}$ collocate - should be described as a Metaphor copolyseme of follow in to follow a person on the street, and absolutely not as a Grammaticalization.

From the viewpoint of diachrony and word creation, one could see both cases of Grammaticalization as results of preliminary polysemic derivations, such as metaphoric derivations. For instance, the intensifier heavy in heavy sigh most probably originates via some form of metaphor from heavy in heavy package. However, we believe that the lexicographic definition of the intensifier heavy should be extremely basic - based on the 'intense' semanteme which is the trigger for the Magn lexical function (Mel'čuk and Polguère in press); it should by no means develop a metaphorbased explanation of the collocate meaning.

Grammaticalization is minimally present in the fr-LN polysemy structures: only four cases. But this is a consequence of incomplete (and sometime erroneous) lexicographic description. At present, Grammaticalization is in all probability largely underrepresented in our data.

\subsubsection{Coderivation}

An $\mathrm{L}_{1}$ Coderivation $\rightarrow \mathrm{L}_{2}$ relation is such that instead of $\mathrm{L}_{2}$ existing in the lexicon in reference to its copolyseme $\mathrm{L}_{1}$, both lexical units are individually derived from a pair of copolysemes of another vocable. Let us exemplify this atypical case of copolysemy relation with the following pair of lexical units borrowed from the fr-LN.

\begin{tabular}{|l|l|l|}
\hline $\mathrm{L}_{1}$ & APPLICABLE I & $\begin{array}{l}\text { Cette crème hydratante est applicable sur tous les types de peau. } \\
\text { 'This moisturizing cream is applicable on all types of skin' }\end{array}$ \\
\hline $\mathrm{L}_{2}$ & APPLICABLE II & $\begin{array}{l}\text { Cette réglementation n'est pas applicable aux mineurs. } \\
\text { 'This regulation is not applicable to minors' }\end{array}$ \\
\hline
\end{tabular}

The adjective applicable $\mathbf{I}$ is, first of all, a semantic (and morphological) derivative of the verb APPLIQUER I ' $X$ puts/spreads Y on Z' and denotes the property of something to be a potential $\mathrm{Y}$ which can be put/spread on a $\mathrm{Z}$. This corresponds to a standard paradigmatic lexical function called $\mathrm{Able}_{2}$ :

$A b l e_{2}($ APPLIQUER I $)=$ APPLICABLE I.

The same paradigmatic derivation holds for APPLICABLE II, derived from APPLIQUER II ' $\mathrm{X}$ makes $\mathrm{Y}$ be effective/relevant as regards to $\mathrm{Z}$ ':

$A b l e_{2}($ APPLIQUER II ) = APPLICABLE II.

In other words, we are faced with the following apparent paradox:

- both adjectives APPLICABLE I and APPLICABLE II clearly belong to the same adjectival vocable APPLICABLE and should be connected by a copolysemy relation in its polysemy structure; 
- the obvious lexical sources in the French lexicon of APPLICABLE I and APPLICABLE II are, respectively, the two copolysemes APPLIQUER I and APPLIQUER II of the verbal vocable APPLIQUER, and the corresponding $\mathrm{Able} \mathbf{e}_{2}$ semantic derivation clearly supersedes - and even overrides - in the network structure of the lexicon any type of copolysemy relation that may connect the two adjectives.

The solution we adopted is to introduce a copolysemy relation, namely Coderivation, which holds a very special status: it exists only in relation to another copolysemy relation present in another vocable of the language. Figure 3 below visualizes this lexical configuration for the APPLICABLE I vs. APPLICABLE II pair of copolysemes.

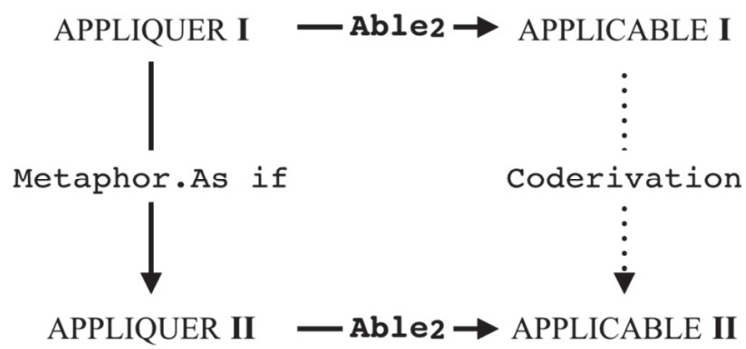

Figure 3. System of lexical relations involving a Coderivation

In an $\mathrm{L}_{1}$ Coderivation $\rightarrow \mathrm{L}_{2}$ copolysemy relation, whether the denotations of $\mathrm{L}_{1}$ and $\mathrm{L}_{2}$ intersect is entirely dependent on the corresponding copolysemy relation in the source vocable. In the case examined above and visualized in Figure 3, the verbs APPLIQUER I and APPLIQUER II are connected by the non-cohesive relation of Metaphor; consequently, the resulting Coderivation relation between the adjectives APPLICABLE I and APPLICABLE II is equally non-cohesive (the denotations of the adjectives do not significantly intersect). Because of this lack of autonomy as regards its semantic weight, Coderivation is not considered as being inherently a case of polysemy derivation.

To conclude on this relation, note that Coderivation is not much present in the fr- $\mathrm{LN}$, but is not that marginal either: it represents close to $2.2 \%$ of all copolysemy relations identified so far.

\section{CONCLUDING REMARKS}

We hope that the present study - as incomplete as it is - offers useful preliminary results on what a lexical network approach to the modeling of polysemy can offer. The strategy that consists in systematically considering lexical relations controlled by copolysemes - i.e. their individual lexical cluster (see Definition 6, Subsection 3.1) is a major characteristic of the lexical network approach. It is, in our opinion, more rigorous than pure intuitive conceptual and semantic reasoning on word senses, which often leads to non-falsifiable modeling. It is also a good way of accounting for lexical variation, e.g. diachronic or individual variation. For instance, the pair BRAS I.1a 'arm of a person' vs. BRAS I.3 'arm of some animals [cf. octopuses]' examined in Subsec- 
tion 3.3.1 may very well be considered by one individual as implicating an Extension relation because she/he perceives intuitively the presence of many shared lexical connections in the clusters of these two lexical units, whereas another individual may not have access to such information and, therefore, interpret the relation as one of Metaphor. In the case of a Lexical System type of model, such as the fr-LN, what matters is the consistency between the diagnosis of a given polysemy relation and the systems of lexical connections - lexical clusters - that position both copolysemes within the topology of the global lexical graph of the language.

Further work that remains to be done includes: (i) validation, refinement and extension of the description of French in the fr-LN; (ii) identical large-scale work on the networks of other languages (English and Russian are next on the list); (iii) extraction of general theoretical principles from these analyses, which will deepen our understanding of polysemy as a universal linguistic phenomenon.

One last word to mention Barque et al. (2018), published at the time of writing of the present paper. It describes a study of regular polysemy based on the extraction of copolysemy templates from the fr-LN and from the Wolf lexical database.

(C) Alain Polguère, 2018

\section{Acknowledgments}

We are extremely grateful to Lucie Barque, Lidija Iordanskaja, Veronika Lux-Pogodalla, Igor Mel'čuk, Ophélie Tremblay and two anonymous reviewers of the Russian Journal of Linguistics for their comments on a preliminary version of this paper. Many thanks to Sandrine Ollinger for the extraction and processing of polysemy data from the fr-LN database. Finally, a very special thank to the staff of the Segafredo café at Telok Ayer Singapore for their excellent coffee, their hospitality and their kindness which contributed significantly to our ability to bring this work to its conclusion.

\section{REFERENCES}

Apresjan, Juri D. (1974). Regular Polysemy. Linguistics 142, 5-32.

Barque, Lucie, Haas, Pauline, Huyghe, Richard (2018). Polysémie régulière et néologie sémantique. Constitution d'une ressource pour l'étude des sens nouveaux. Neologica 12, 91-108.

Bréal, Michel (1897). Essai de sémantique: science des significations. Paris: Hachette.

Béjoint, Henri (1990). Monosemy and the Dictionary. In Tamás Magay and Judit Zigány (eds.): BudaLEX'88 Proceedings. Papers from the $3^{\text {rd }}$ International EURALEX Congress, Budapest: Akadémiai Kiadó, 13-26.

Courbon, Bruno (2015). Sur l'histoire du terme polysémie. 1: Genèse(s) du concept. Langues et linguistique 35, 1-23.

Cruse, D. Alan (1995). Polysemy and Related Phenomena from a Cognitive Linguistic Viewpoint. In Patrick Saint-Dizier and Evelyn Viegas (eds.): Computational Lexical Semantics. Cambridge et al.: Cambridge University Press, $33-49$.

Falkum, Ingrid Lossius, Vicente, Agustin (2015). Polysemy: Current perspectives and approaches. Lingua $157,1-16$.

Fellbaum, Christiane D. (ed.) (1998). WordNet: An Electronic Lexical Database. Cambridge, MA: The MIT Press.

Gader Nabil, Ollinger, Sandrine, Polguère Alain (2014). One Lexicon, Two Structures: So What Gives? In Heili Orav, Christiane D. Fellbaum and Piek Vossen (eds.): Proceedings of the Seventh Global Wordnet Conference (GWC2014), Global WordNet Association, Tartu, 163-171. 
Geeraerts, Dirk (1994). Polysemy. In Ron E. Asher and James M. Y. Simpson (eds.): Encyclopedia of Language and Linguistics. Oxford, UK: Pergamon, 3227-3228.

Goddard, Cliff (2000). Polysemy. A Problem of Definition. In Yael Ravin and Claudia Leacock (eds.): Polysemy: Theoretical and Computational Approaches. Oxford: Oxford University Press, $129-151$.

Goddard, Cliff (2011). Semantic Analysis. A Practical Introduction. $2^{\text {nd }}$ edition, Oxford Textbooks in Linguistics. Oxford, UK: Oxford University Press.

Goddard, Cliff, Wierzbicka, Anna (eds.) (2002). Meaning and Universal Grammar: Theory and Empirical Findings. Volumes I, II. Studies in Language Companion Series 60. Amsterdam/ Philadelphia: John Benjamins.

Goddard, Cliff, Wierzbicka, Anna (2014). Words and Meanings: Lexical Semantics Across Domains, Languages, and Cultures. Oxford UK: Oxford University Press.

Gries, Stefan Th. (2015). Polysemy. In Ewa Dąbrowska and Dagmar S. Divjak (eds.): Handbook of Cognitive Linguistics. Handbücher zur Sprach- und Kommunikationswissenschaft / Handbooks of Linguistics and Communication Science (HSK) 39. Berlin/Boston: De Gruyter Mouton, $472-490$.

Hanks, Patrick (2013). Lexical Analysis. Norms and Exploitations. Cambridge, MA/London, UK: The MIT Press.

Hénault, Christine (2008). Eating Beyond Certainties. In Vanhove (2008), 291-301.

Ingrosso, Francesca, Polguère, Alain (2015). How Terms Meet in Small-World Lexical Networks: The Case of Chemistry Terminology. Proceedings of the $11^{\text {th }}$ International Conference on Terminology and Artificial Intelligence (TIA 2015), Granada, 167-171.

Krylosova, Svetlana (2017). Du projet d'élaboration d'un Réseau lexical du russe (RL-ru). Karpovskie naučnye čtenija 11(1), 243-246.

Ludlow, Peter (2014). Living Words. Meaning Underdetermination and the Dynamic Lexicon. Oxford, UK: Oxford University Press.

Lux-Pogodalla, Veronika, Polguère, Alain (2011). Construction of a French Lexical Network: Methodological Issues. Proceedings of the First International Workshop on Lexical Resources, WoLeR 2011. An ESSLLI 2011 Workshop, Ljubljana, 54-61.

Mel'čuk, Igor (1989). Semantic Primitives from the Viewpoint of the Meaning-Text Linguistic Theory. Quaderni di Semantica 10(1), 65-102.

Mel'čuk, Igor (1996). Lexical Functions: A Tool for the Description of Lexical Relations in the Lexicon. In Leo Wanner (ed.): Lexical Functions in Lexicography and Natural Language Processing. Language Companion Series 31, Amsterdam/Philadelphia: John Benjamins, 37-102.

Mel'čuk, Igor (2006a). Explanatory Combinatorial Dictionary. In Giandomenico Sica (ed.): Open Problems in Linguistics and Lexicography. Monza: Polimetrica, 225-355.

Mel'čuk, Igor (2006b). Aspects of the Theory of Morphology. Trends in Linguistics. Studies and Monographs 146. Berlin \& New York: Mouton de Gruyter.

Mel'čuk, Igor (2007). Lexical Functions. In Harald Burger, Dmitrij Dobrovol'skij, Peter Kuhn and Neal Norrrick (eds.): Phraseologie / Phraseology: Ein Internationales Handbuch Zeitgenössischer Forschung / an International Handbook of Contemporary Research. Berlin/ New York: Walter de Gruyter, 119-131.

Mel'čuk, Igor (2013). Semantics: From Meaning to Text. Volume 2. Studies in Language Companion Series 135. Amsterdam/Philadelphia: John Benjamins.

Mel'čuk, Igor, Clas, André, Polguère, Alain (1995). Introduction à la lexicologie explicative et combinatoire. Paris/Louvain-la-Neuve: Duculot. 
Mel'čuk, Igor et al. (1984, 1988, 1992, 1999). Dictionnaire explicatif et combinatoire du français contemporain. Recherches lexico-sémantiques I, II, III, IV. Montreal: Les Presses de l'Université de Montréal.

Mel'čuk, Igor, Polguère, Alain (In press). Theory and Practice of Lexicographic Definition. Journal of Cognitive Science.

Mel'čuk, Igor, Zholkovsky, Alexander (1984). Explanatory Combinatorial Dictionary of Modern Russian. Semantico-syntactic Studies of Russian Vocabulary. Vienna: Wiener Slawistischer Almanach.

Navigli, Roberto, Ponzetto, Simone Paolo (2012). BabelNet: The Automatic Construction, Evaluation and Application of a Wide-Coverage Multilingual Semantic Network. Artificial Intelligence 193, 217-250.

Picoche, Jacqueline (1993) La cohérence des polysèmes, un outil pour débloquer l'enseignement $\mathrm{du}$ vocabulaire. Repères $8,11-28$.

Polguère, Alain (2009) Lexical Systems: Graph Models of Natural Language Lexicons. Language Resources and Evaluation 43(1), 41-55.

Polguère, Alain (2014). From Writing Dictionaries to Weaving Lexical Networks. International Journal of Lexicography 27(4), 396-418.

Polguère, Alain (2015). Lexical Contextualism: The Abélard Syndrome. In Núria Gala, Reinhard Rapp and Gemma Bel-Enguix (eds.): Language Production, Cognition, and the Lexicon. Text, Speech and Language Technology 48, Cham Heidelberg New York Dordrecht London: Springer, 53-73.

Polguère, Alain (2016a). Lexicologie et sémantique lexicale. Notions fondamentales. $3^{\text {rd }}$ edition, Montreal: Les Presses de l'Université de Montréal.

Polguère, Alain (2016b). La question de la géométrie du lexique. SHS Web of Conferences 27, 01002 [F. Neveu et al.: Proceedings of the " $5^{e}$ Congrès Mondial de Linguistique Française (CMLF 2016)", Tours].

Sigman, Mariano, Cecchi, Guillermo A. (2002). Global Organization of the Wordnet Lexicon. Proceedings of the National Academy of Sciences of the United States of America 99(3), $1742-1747$.

Traugott, Elizabeth Closs, Dasher, Richard B. (2001). Regularity in Semantic Change. Cambridge Studies in Linguistics 97, Cambridge UK: Cambridge University Press.

Ullmann, Stephen (1959). Sémantique et étymologie. Cahiers de l'Association internationale des études françaises 11, 323-335.

Vanhove, Martine (ed.) (2008). From Polysemy to Semantic Change. Studies in Language Companion Series 106. Amsterdam/Philadelphia: John Benjamins.

Watts, Duncan J., Strogatz, Steven H. (1998). Collective dynamics of 'small-world' networks. Nature $393,440-442$.

Wierzbicka, Anna (1985). Lexicography and Conceptual Analysis. Ann Arbor, MI: Karoma.

Wierzbicka, Anna (1987). English Speech Act Verbs: A semantic dictionary. Sydney: Academic Press.

Wierzbicka, Anna (1992). Back to Definitions: Cognition, Semantics, and Lexicography. Lexicographica 8, 146-174.

Wierzbicka, Anna (1996). Semantics: Primes and Universals. Oxford, UK: Oxford University Press.

Zalizniak, Anna A. (2007). The Phenomenon of Polysemy and Ways to Describe It. In Marina Rakova, Gergely Pethö and Csilla Rákos (eds.): The Cognitive Basis of Polysemy. New Sources of Evidence for Theories of Word Meaning. Metalinguistica 19, Frankfurt am Main et al:: Peter Lang, 93-121. 


\section{Article history:}

Received: 25 September 2018

Revised: 20 October 2018

Accepted: 10 November 2018

\section{История статьи:}

Дата поступления в редакцию: 25 сентября 2018

Дата принятия к печати: 10 ноября 2018

\section{For citation:}

Polguère, Alain (2018). A Lexicographic Approach to the Study of Copolysemy Relations. Russian Journal of Linguistics, 22 (4), 788 - 820. doi: 10.22363/2312-9182-2018-22-4-788-820.

\section{Для цитирования:}

Polguère, Alain. A Lexicographic Approach to the Study of Copolysemy Relations // Вестник Российского университета дружбы народов. Серия: Лингвистика. = Russian Journal of Linguistics. 2018. T. 22. № 4. C. 788 - 820. doi: 10.22363/2312-9182-2018-22-4-788-820.

\section{Bionote:}

ALAIN POLGUÈRE did his PhD in linguistics at the Université de Montréal (Montreal, Canada) on the semantics-syntax interface in computer text generation. After graduating, he began an academic career, first at the National University of Singapore (1991-1995), then at the Universite de Montréal (1995-2010). There, he founded in 1997 with Igor Mel'čuk the Observatoire de linguistique Sens-Texte (OLST). Since 2009, he is Professor at the Université de Lorraine (Nancy, France) and at the ATILF CNRS research laboratory of Nancy. He is a senior member of the Institut Universitaire de France (IUF). His research interests embrace lexicology, computational lexicography, phraseology, semantics-syntax interface, lexical networks, vocabulary learning/teaching.

Contact information: alain.polguere@univ-lorraine.fr

\section{Сведения об авторе}

АЛЕН ПОЛЬГЕР защитил докторскую диссертацию в Монреальском университете (Монреаль, Канада) по семантико-синтаксическому взаимодействию в создании компьютерных текстов. Академическую карьеру начал в Национальном университете Сингапура (1991-1995), затем работал в Монреальском университете (1995-2010). Там в 1997 году вместе с Игорем Мельчуком основал Лингвистическую лабораторию Смысл - Текст (OLST). С 2009 года является профессором Лотарингского университета (Нанси, Франция) и исследовательской лаборатории ATILF CNRS Нанси, а также старшим научным сотрудником исследовательского института Institut Universitaire de France (IUF). Его научные интересы охватывают лексикологию, компьютерную лексикографию, фразеологию, семантико-синтаксическое взаимодействие, изучение / преподавание лексики.

Контактная информация: alain.polguere@univ-lorraine.fr 